\title{
Rhizoremediation as a green technology for the remediation of petroleum hydrocarbon-contaminated soils
}

Son A. Hoang a,e, Dane Lamb a,b, Balaji Seshadri a,b, Binoy Sarkar c , Girish Choppala

${ }^{a}$, M.B. Kirkham ${ }^{d}$, Nanthi S. Bolan ${ }^{a, b,{ }^{*}}$

a Global Centre for Environmental Remediation (GCER), Advanced Technology Centre (ATC) Building, Faculty of Science, The University of Newcastle, University Drive, Callaghan, NSW 2308, Australia

${ }^{b}$ Cooperative Research Centre for Contamination Assessment and Remediation of Environment (CRC CARE), The University of Newcastle, PO Box 18, Callaghan, NSW 2308, Australia

c Lancaster Environment Centre, Lancaster University, Lancaster LA1 4YQ, United Kingdom

d Department of Agronomy, Kansas State University, Manhattan, KS, United States

e Division of Urban Infrastructural Engineering, Mien Trung University of Civil Engineering, Phu Yen 56000, Viet Nam

* Corresponding author at: Global Centre for Environmental Research, Advanced Technology Centre (ATC) Building, Faculty of Science, The University of Newcastle, University Drive, Callaghan, NSW 2308, Australia.

E-mail address: Nanthi.Bolan@newcastle.edu.au (Nanthi Bolan). 
Highlights

- Recalcitrant fractions of petroleum hydrocarbon (TPH) cometabolized for remediation

- Biostimulation provides propitious environment for degraders in the rhizosphere

- Bioaugmentation can supplement the catabolic activities of rhizosphere communities

- Effective rhizoremediation requires the modulation of plant-microbial associations

- Rhizoremediation of TPH-contaminated sites is a risk-based phytomanagement strategy 


\section{BIOSTIMULATION}

\section{BIOAUGMENTATION}

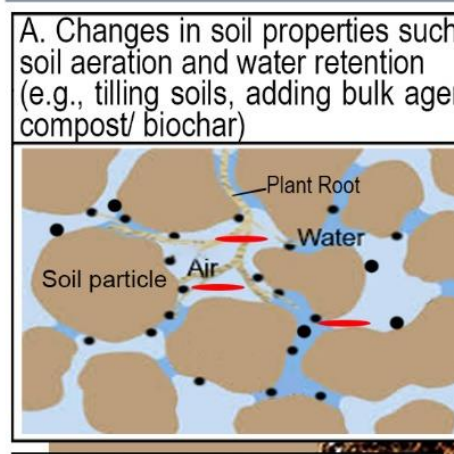

B. Nutritional additions of inorganic and/or organic fertiliser (e.g., NPK/ slow release/ biochar/compost fertilisers)

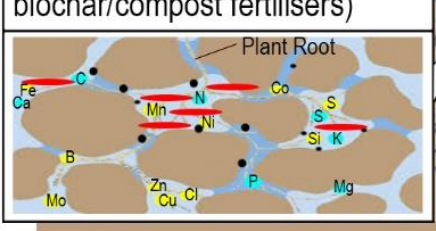

C. Enhancement of TPH bioavailability (e.g., adding root exudates/ surfactants/ surfactant-like compounds)

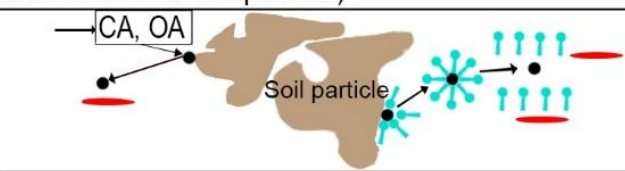

- Petroleum hydrocarbons isurfactant monomer Indigenous microorganisms $\sim$ Introduced microorganisms 


\section{ABSTRACT}

Rhizoremediation is increasingly becoming a green and sustainable alternative to physico-chemical methods for remediation of contaminated environments through the utilization of symbiotic relationship between plants and their associated soil microorganisms in the root zone. The overall efficiency can be enhanced by identifying suitable plant-microbe combinations for specific contaminants and supporting the process with the application of appropriate soil amendments. This approach not only involves promoting the existing activity of plants and soil microbes, but also introduces an adequate number of microorganisms with specific catabolic activity. Here, we reviewed recent literature on the main mechanisms and key factors in the rhizoremediation process with a particular focus on soils contaminated with total petroleum hydrocarbon $(\mathrm{TPH})$. We then discuss the potential of different soil amendments to accelerate the remediation efficiency based on biostimulation and bioaugmentation processes. Notwithstanding some successes in well-controlled environments, rhizoremediation of TPH under field conditions is still not widespread and considered less attractive than physicochemical methods. We catalogued the major pitfalls of this remediation approach at the field scale in TPH-contaminated sites and, provide some applicable situations for the future successful use of in situ rhizoremediation of TPH-contaminated soils.

KEY WORDS: Biostimulation; Bioaugmentation; Field application; Rhizosphere; Soil amendments

ABBREVIATIONS: AMF (Arbuscular mycorrhiza fungi); B[a]P (Benzo(a)pyrene); CA (Citric acid); CK (Cytokinins); DGGE (Denaturing Gradient Gel Electrophoresis); GA (Gibberellins); HMW (High molecular weight); IAA (Indole-3-acetic acid); LMW 
(Low molecular weight); LMWOAs (Low molecular weight organic acids); OA (Oxalic acid); PGP (Plant growth promoting); SIP (Stable Isotope Probing); TPH (Total petroleum hydrocarbon)

\section{Introduction}

Global industrial growth and increasing use of petroleum fossil fuels (gasoline, creosote, diesel, and petrol) have resulted in exorbitant environmental contamination with hydrocarbon compounds. While being primarily derived from crude oil, total petroleum hydrocarbon (TPH) is a measure of the complex mixture of different hydrocarbon compounds (Figure 1). The TPH is also considered as one of the most common groups of persistent organic pollutants (Kuppusamy et al. 2020; Patowary et al. 2017). This contaminant group is made up of gasoline range organics (GRO) including small chain hydrocarbons (C6-C10) such as benzene, toluene, ethylbenzene, and xylene (BTEX), diesel range organics (DRO) comprising long chain hydrocarbons (C10-C40), and compounds such as polycyclic aromatic hydrocarbons (PAHs) (Kamath et al. 2004a). Thus, TPH consists of both aliphatic (e.g., alkane, alkene, alkyne) and aromatic hydrocarbons (Truskewycz et al. 2019), which are mainly recalcitrant in nature and are classified as priority pollutants (Falkova et al. 2016; Varjani 2017).

Due to industrial activities such as the processes of extraction, refining, transport and use, and accidental oil spills, an increasing number of sites are seriously contaminated by TPH worldwide (Pinedo et al. 2013; Wang et al. 2014). In Australia, nearly 80,000 sites are impacted by petroleum hydrocarbon pollutants (NEPC 1999), whereas in Western Europe, petroleum hydrocarbons are one of the major 
soil contaminants present in at least 342,000 contaminated sites (Panagos et al. 2013). In the USA, $90 \%$ of the contaminated sites are linked to petroleum hydrocarbons (Stroud et al. 2007). The TPH contamination in the environment can result in adverse effects on human and ecological health (Bruederle and Hodler 2019; Chen et al. 2015; Marchand et al. 2018), and may cause death or mutations of living cells (Nardeli et al. 2016; Rein et al. 2016). For instance, BTEX are acutely toxic and can affect the central nervous system of humans and animals (Hunt et al. 2018). Polycyclic aromatic hydrocarbons, such as benzo[a]pyrene $(B[a] P)$, are recognized as mutagens and carcinogens for humans and animals subjected to continuous long-term exposure (Beal et al. 2019; Chepelev et al. 2015). Furthermore, recent studies underline that the presence of TPH in soils not only adversely affects plant growth and development (Lin et al. 2016; Sivaram et al. 2018) but also impacts soil properties, thereby affecting the diversity and functions of soil microorganisms (Alrumman et al. 2015; Andreolli et al. 2015; Mena et al. 2016). As a consequence, TPH pollution urgently calls for effective and low-cost technologies for the sustainable management of these compounds in the environment, which are beyond the currently used expensive and environmentally disruptive remediation methods (e.g., excavation, incineration) (Gaskin and Bentham 2010; Pizarro-Tobías et al. 2015).

Insert Figure 1 here

Within the scope of the remediation of organic contaminants, bioremediation is an important environmental service where biological agents (e.g., microorganisms, plants) detoxify, degrade, or transform organic pollutants including TPH to innocuous compounds such as $\mathrm{CO}_{2}, \mathrm{CH}_{4}, \mathrm{H}_{2} \mathrm{O}$, and biomass, without adversely affecting the environment (Azubuike et al. 2016; Macaulay and Rees 2014; Ron and 
Rosenberg 2014; Varjani et al. 2014). Although bioremediation of TPH can occur naturally in the absence of plants, this process is usually slow and inefficient because relatively low numbers of degradative microorganisms are present in most of the contaminated soils (Miettinen et al. 2019; Mikolasch et al. 2019). The natural bioremediation process is also limited by TPH bioavailability, i.e., the quantity of TPH which is freely available to cross the cellular membrane of an organism from the surrounding medium for the bioremediation to occur (Imron et al. 2019). In addition, the bioremediation efficiency may be limited especially when soils are contaminated with other recalcitrant compounds such as PAHs (Hussain et al. 2018b; Smułek et al. 2020). Bioavailability and recalcitrance reflect the intrinsic properties of the mixed hydrocarbon contaminants and associated individual samples (Cuypers et al. 2001). Several researchers used different approaches to evaluate bioavailability of hydrocarbons including solvent extraction, cyclodextrin extraction, supercritical carbon dioxide extraction, persulfate oxidation and solid phase extraction (Chung and Alexander 1999; Cuypers et al. 2002; Hawthorne et al. 2000; Reid et al. 2000). However, Cuypers et al. (2001) found that persulfate oxidation was not suitable for predicting TPH bioavailability as persulfate was unable to oxidize hydrocarbons with a high ionization potential. They concluded that the above method can be suitable for estimating bioavailability of PAHs.

Where microorganisms alone cannot effectively remediate the TPH contamination, plant-assisted bioremediation (phytoremediation) is a promising technique that uses plants and their associated microorganisms for environmental remediation. Different plant species can facilitate remediation of contaminated sites through various processes such as phytovolatilization (i.e., the release of pollutants by plants in volatile form), phytodegradation (i.e., the breakdown of pollutants by plant enzymes, 
usually inside tissues), phytostabilization (i.e., the stabilization or containment of mobile pollutants in the soil), phytoextraction (i.e., the use of plants to clean up pollutants via accumulation in harvestable tissues), and rhizodegradation or rhizoremediation (i.e., the degradation of organic pollutants in the root zone (rhizosphere) of plants (Cunningham et al. 1995; Pilon-Smits 2005). Among the above, which mechanism becomes prevalent in a particular situation would depend on the soil properties, type of plant species used, and the characteristics of the contaminant (Newman and Reynolds 2004). In the case of TPH-contaminated soils, rhizoremediation is widely accepted as an effective mechanism for TPH removal, and it can result in a complete mineralization of pollutants (Correa-García et al. 2018; Kamath et al. 2004a; Kiamarsi et al. 2020; Thijs et al. 2016). The highly hydrophobic nature of TPH and its possible sorption limit the ability of microorganisms to access the contaminants. Hence, root exudates (e.g., organic acids, enzymes, protons, sugars) from plants will not only support the growth of microorganisms, but also enhance the microbial activity in the rhizosphere, thereby providing complete mineralization of TPH. Moreover, the synergistic relationship between plants and their associated rhizosphere microbial communities can support greater plant resilience against contaminants, through better assimilation of nutrients and/or reduction of oxidative stress in plants (Gkorezis et al. 2016; Hutchinson et al. 2003; Merkl et al. 2005b).

However, plants require additional care in the form of agronomic intervention and other strategies to limit the effect of contaminants on plant growth, thereby ensuring growth in the early stages. Despite some review papers in the field of TPH rhizoremediation, most of the current researches have targeted on either one specific group of TPH (i.e., PAHs) (Turkovskaya and Muratova 2019), or focused 
on plants (Martin et al. 2014) or rhizosphere microorganisms (Correa-García et al. 2018; dos Santos and Maranho 2018), or considered enhancing bioremediation efficiency in the absence of plants (Hussain et al. 2018c). In addition, the potential use of introduced microorganisms with respect to the enhancement of plant growth and functions, and their associated microorganisms in rhizoremediation process, is still lacking. The main objective of this present review is to summarize different mechanisms by which plants and their rhizosphere microorganisms remediate TPHimpacted soils. It focused on plant-microorganism beneficial synergic interactions. Furthermore, we discussed in detail the potential approaches to enhance simultaneously plant growth and microbial activity in the rhizosphere. Finally, some potential benefits of providing holistic remediation techniques, and the pitfalls of exploiting rhizoremediation on the field scale, are also discussed.

\section{Rhizoremediation: a combined use of phytoremediation and microbial}

\section{degradation}

Rhizoremediation involves the use of specific plants and their associated rhizosphere microorganisms for degrading target pollutants. Plants act indirectly in this process by stimulating the catalytic activities of the microorganisms through root exudates (Lacalle et al. 2018; Pilon-Smits 2005). By definition, the rhizosphere refers to the extremely active soil zone surrounding the roots $(1-2 \mathrm{~mm})$ influenced by plant activity (Brink 2016; Razavi et al. 2016). Excellent comprehensive reviews on the rhizosphere processes are available in the literature (Bais et al. 2006; Kai et al. 2016; Lugtenberg and Bloemberg 2004); hence, only a brief description of important rhizosphere characteristics regarding organic contaminant degradation is mentioned below. The principle behind rhizoremediation can be described as follows: plant roots provide a nutrient- and carbon-rich environment wherein 
microbial activity is stimulated, and, in return, some of the microorganisms facilitate the degradation of contaminants (Newman et al. 2016; Qixing et al. 2011; Sillen et al. 2015).

\subsection{Root exudates and rhizosphere effect}

It has been long known that plant roots can release between 6 to $21 \%$ of photosynthetically fixed carbon into the rhizosphere (rhizodeposition) (Bertin et al. 2003; Chowdhury et al. 2014; Huang et al. 2014). Plant roots can actively or passively secrete a wide range of organic compounds such as amino acids, organic acids, sugars, phenolic compounds, polysaccharides, and humic compounds, which are collectively referred to as root exudates (Herz et al. 2018; Sun et al. 2012). The composition and quantity of plant root exudates vary depending on the plant species, age and health of the plants, and several external biotic and abiotic factors (Dietz et al. 2019; Liu et al. 2019). Rhizodeposition can generally be classified into four distinct groups based on their modes of production: passive exudates, secondary plant metabolites, mucilages (from root tip and epidermal cells), and lysates (from senescent tissues and roots) (Bertin et al. 2003; Martin et al. 2014). Since most of these compounds can be readily utilized as energy and carbon sources, soil microorganisms are attracted to these substrates through chemotaxis, leading to their proliferation and subsequent metabolism (Chaudhry et al. 2005; Huang et al. 2014; Lioussanne et al. 2008). Nonetheless, owing to the formation of reactive oxygen species (ROS) by respiration of root cells, the rhizosphere remains as an oxidatively stressful environment (Segura and Ramos 2013). Therefore, only competent microorganisms that can utilize plant root-derived compounds and tolerate the toxicity of ROS are selectively enriched within this highly competitive

environment (Berg and Smalla 2009; el Zahar Haichar et al. 2008; Sousa et al. 
2020). Consequently, the rhizosphere is up to 100 times richer in microbial biomass and activity but poorer in diversity than the non-rhizosphere (bulk) soil, and this refers to "rhizosphere enrichment effect" (Fan et al. 2017; Kowalchuk et al. 2002; Martin et al. 2014; Nie et al. 2010).

Not only solely benefiting the microorganisms, root exudation can also benefit the plant itself (Correa-García et al. 2018). It has been shown that plants can regulate the microbial composition in the rhizosphere (Vieira et al. 2020), foster certain beneficial microbes, change the chemical and physical soil properties (Vives-Peris et al. 2019), and inhibit the growth of competing plant species (Schandry and Becker 2019) through root exudates. As different plant species stimulate a different set of microorganisms, it is suggested that plants control their rhizosphere microbial composition (Dagher et al. 2019; Ofek-Lalzar et al. 2014). Although specific communication and recognition processes between plants and rhizosphere microorganisms have long been described in agricultural, non-contaminated soils, little is known about the interactions between plants and contaminant-degrading microorganisms in the rhizosphere in contaminated soils (Segura and Ramos 2013). Generally, plants exposed to contaminated environments respond by increasing their root exudation, which may play an important role in selecting contaminant-degrading microorganisms in their rhizosphere (Esperschütz et al. 2009; Yergeau et al. 2014). Additionally, root colonization of these microorganisms allows their further distribution and spread to other extended soil areas (Bais et al. 2006). Thus, plant root exudates can direct the recruitment of a beneficial rhizosphere microbiome, which may be responsible for increased metabolic degradation rate of certain xenobiotic compounds (Correa-García et al. 2018; Gaskin and Bentham 2010). Indeed, Siciliano et al. (2001) stated that the type and 
amount of contaminants and plant genotypes can affect the enrichment of appropriate catabolic gene-carrying bacteria in the rhizosphere. For example, the diversity of ring-cleavage dioxygenase genes in the rhizosphere of birch (Betula pendula) was higher than that in the bulk soil in a pyrene-contaminated soil (Sipilä et al. 2008).

Apart from actively modulating the composition, diversity, and activity of rhizosphere microorganisms, root exudates can also improve the availability of organic contaminants for microbial metabolism (Correa-García et al. 2018; Martin et al. 2014). For instance, Gao et al. (2010a) found that, by the addition of citric acid (CA) and oxalic acid (OA) (two major constituents of root exudates), there was an increase in the release of phenanthrene and pyrene from soil particles, which was attributed to the competitive desorption by these two organic acids. Not only that, many secondary plant metabolites found in the rhizosphere such as flavonoids and phenols are analogous to organic contaminants (Hussain et al. 2018c; Singer et al. 2003); therefore, microbial genes relevant to the degradation of organic pollutants can often be enriched within the rhizosphere, even in uncontaminated soils (Yergeau et al. 2014). Indeed, some of the root-released aromatic compounds are inducers of degradation pathways by rhizosphere microorganisms (Sun et al. 2010). For instance, Toyama et al. (2011) reported that there was a strong association between increasing phenolic root exudates and higher $\mathrm{B}[\mathrm{a}] \mathrm{P}$ degradation rates in the cosmopolitan common reed (Phragmites australis) rhizosphere. Likewise, phenolic compounds (e.g., morin, caffeic, and protocatechuic acid) were linked to the bacterial degradation of 3- and 4-ring PAHs in the rhizosphere of wheat (Triticum aestivum) and cucurbit (Cucurbita pepo) plants (Ely and Smets 2017). Although having a rich source of published literature on this topic, our understanding is still 
inadequate because the rhizosphere is a highly dynamic environment where quantity and nature of root exudates, microbial composition, and other factors such as $\mathrm{pH}$, soil structure and soil macroorganisms are constantly changing. Furthermore, rhizosphere microorganisms thrive and perform their functions based on their interactions with plants, other microorganisms, and the environment. In this highly dynamic nutritional environment, microorganisms are not only competing for limited nutrient and carbon sources and exposed to relatively high levels of putative toxic compounds from plant exudates, but also suffering from the toxicity of the concerned contaminant if living in contaminated soils (Segura et al. 2009).

\subsection{Mechanisms of TPH degradation in the rhizosphere}

The hydrophobic characteristics of almost all TPH compounds result in high retention in the root zone soil through strong adsorption to organic matter. Thus, biodegradation in the rhizosphere is believed to be one of the main mechanisms for reducing the concentration of TPH in impacted soils (Correa-García et al. 2018; dos Santos and Maranho 2018; Thijs et al. 2016). As discussed below, several biochemical processes occurring in the plant roots' immediate vicinity provide an ideal environment for TPH degradation (Hussain et al. 2018c).

\subsubsection{Plant extracellular enzymes}

Root exudates can directly participate in the degradation of organic pollutants by releasing a range of enzymes such as dehalogenases, laccases, peroxidases, nitrilases, nitroreductases, phosphatases, and cytochrome P450 monooxygenases that can transform organic xenobiotics (Table 1). Of these enzymes, laccases and peroxidases have been extensively studied for their applicability in remediation of TPH-impacted soils (Dubrovskaya et al. 2017; Luo et al. 2018; Muratova et al. 2015; 
Muratova et al. 2009). For example, plant-secreted enzymes such as laccases and peroxidases participate in the oxidation of various PAHs (common in fuel mixtures), which is an essential prerequisite for further metabolism (Balasubramaniyam 2015; Martin et al. 2014). However, in contrast to research on microbial degradation of TPH in the rhizosphere, studies on plant root extracellular enzymatic reactions with $\mathrm{TPH}$ are limited. There have been only a few investigations on the degradation of petroleum hydrocarbons by the original plant root exudates. For instance, Muratova et al. (2009) showed that in a phenanthrene-contaminated environment, the activity of oxidoreductases (e.g., laccases, tyrosinases, peroxidases) in sorghum (Sorghum bicolor L. Moench) root exudates increased as phenanthrene concentration in the soil increased. The authors found that the plant enzymes were mainly involved in the oxidation of the $\mathrm{PAH}$, and the initial attack on the contaminant was predominantly performed by soil microbial enzymes. Similarly, oxidoreductases (mostly peroxidases) were actively involved in the oxidation of phenanthrene and its microbial metabolites in the rhizosphere of alfalfa (Medicago sativa) (Muratova et al. 2015). Interestingly, although the major peroxidases derived from root exudates of sorghum and alfalfa are typical plant peroxidases, they are different in terms of ionic status. Therefore, while cationic sorghum peroxidases play the main role in the catabolism of parent PAHs, anionic alfalfa peroxidases are the main players in the oxidation of the PAHs derivatives (Dubrovskaya et al. 2017).

Although plant roots can directly act upon contaminants in soils, they are sometimes susceptible to contaminant-derived stresses and requires protection from soil microorganisms (Begum et al. 2019). Arbuscular mycorrhizal fungi (AMF) are ubiquitous and form symbiotic association with roots of plant species (Boldt-Burisch et al. 2018; Lenoir et al. 2016). Their presence are of particular importance when 
plants are under environmental stress such as contamination with petroleum hydrocarbons (Garcés-Ruiz et al. 2019; Iffis et al. 2016). On one hand, similar to their host plants, some AMF release enzymes (e.g., peroxidases, laccases, catalases) participating in the dissipation of TPH molecules (Abbaspour et al. 2020; Xun et al. 2015). For example, all four fungal strains namely Aspergillus niger 'asemoA', Talaromyces purpurogenus 'asemoF', Trichoderma harzianum 'asemoJ', and Aspergillus flavus 'asemoM' isolated from the rhizosphere of some grass species in aged oil spill sites in Nigeria showed catalase, peroxidase, and laccase activities. It was shown that the enzyme concentrations increased with increasing crude oil concentrations (Asemoloye et al. 2018). The authors also reported that these enzymes take part in the degradation of the crude oil. More surprisingly, these strains were even able to tolerate $20 \%(\mathrm{w} / \mathrm{w})$ crude oil in the culture medium and the tolerance could be explained by their ability to degrade and utilize the hydrocarbons as an energy source (Asemoloye et al. 2018). On the other hand, the AMF may also cause an induction of root peroxidase production by their host plants that are involved in hydrocarbon metabolization (Driai et al. 2015; Ingrid et al. 2016). For instance, wheat mycorrhized by Rhizophagus irregularis showed higher peroxidase activity in the rhizosphere than that in the non-inoculated plant treatment. Higher PAH and alkane degradation were also obtained in $R$. irregularisinoculated wheat by comparison to non-inoculated wheat (Ingrid et al. 2016). Taken together, these results demonstrated the potential of fungal extracellular enzymes to take part in rhizodegradation of petroleum hydrocarbons in the plant rhizosphere. Insert Table 1 here

\subsubsection{Enhancement of pollutant bioavailability}


Once released into the soil environment, the natural weathering of the petroleum hydrocarbons can take place that may alter their chemical composition and redistribution in the soil (Khan et al. 2018; Trindade et al. 2005). This process results in an increase in the relative persistence of high molecular weight hydrocarbons in the soil over time (Ollivier and Magot 2005). Being weakly polar hydrophobic compounds and sparingly soluble in water, TPH are retained strongly within the soil organic matter and thus are not readily available for microbial attack (Correa-García et al. 2018; Kamath et al. 2004a). The importance of desorption and mobilization of TPH is, therefore, believed to be paramount for enhancing the compounds' bioavailability in contaminated soils (Ling et al. 2015). Because hydrocarbon weathering results in increased immobilization, the rhizoremediation of TPH is often limited by the resultant progressively lower bioavailability over time. Therefore, enhanced desorption in the rhizosphere could be considered as a promising approach to overcome this constraint (dos Santos and Maranho 2018; Razavi et al. 2016).

Low-molecular-weight organic acids (LMWOAs), the most active components of root exudates, are abundant in the rhizosphere environment (Gao et al. 2015; Jia et al. 2016). Interestingly, some of these organic compounds are recognized to enhance the desorption of hydrophobic organic compounds including TPH from soils, and hence alter the TPH bioavailability (Jia et al. 2016; Ling et al. 2015; Sun et al. 2012). Among LMWOAs in the exudates, citric acid, oxalic acid and malic acid have been frequently investigated since they are often observed with high concentrations in TPH-contaminated rhizosphere soils and their potential in desorption and extractability of TPH in soils is relatively high (Gao et al. 2010b; Gao et al. 2011; Sun et al. 2012). 
The mechanisms responsible for LMWOA-induced TPH desorption are not well understood (Martin et al. 2014). Nevertheless, it has been assumed that LMWOAs can break the linkage bonds between metallic cations and soil organic molecules (e.g., cation bridging), resulting in the release of soil organic matter into the solution (Gao et al. 2015; Ling et al. 2015). In the case of TPH, metal cations present in soils can form complexes with TPH functional groups, and this association serves as the "bridges" connecting the TPH molecules to soil minerals rendering them unavailable to microorganisms (Saison et al. 2004; Sun et al. 2012). However, when released into the rhizosphere, LMWOAs have a tendency to bind more strongly with the metal cations in the soil resulting in the release of soil mineral-bound TPH molecules (Gao et al. 2010a; Gao et al. 2015; Krishnamurti et al. 1997). In addition, some LMWOAs also play an essential role in the dissolution of soil minerals, which theoretically can break the mineral-TPH association (Bolan et al. 1994; Drever and Stillings 1997; Gao et al. 2010b). As a consequence, the addition of LMWOAs to TPH-impacted soils could promote the release of TPH molecules into the soil solution phase, leading to enhanced extractability and bioavailability of the associated TPH residues in soils (Gao et al. 2010b; Ling et al. 2015).

\subsubsection{Co-metabolism of recalcitrant TPH fraction}

Generally, persistent compounds in TPH are very difficult to be degraded by microorganisms. However, microbial co-metabolism has been shown to serve as an important approach for rhizoremediation of some recalcitrant environmental contaminants such as PAHs (Hussain et al. 2018c; Luo et al. 2014). Microbial cometabolic degradation is referred to as the biodegradation of organic compounds by microorganisms in the presence of primary energy sources (growth substrate), 
and it is regarded as a principal mechanism behind biodegradation of many organic compounds including TPH (Kuiper et al. 2004; Luo et al. 2014).

Recalcitrant fractions of TPH, such as high molecular weight PAHs, do not serve as a carbon or energy source for microorganisms during the biodegradation and thus they must be co-metabolized for remediation (Soleimani et al. 2010). Fortunately, in the rhizosphere, several plant-derived compounds from root exudates, in general, and plant secondary metabolites, in particular, have structures similar to those of the hydrocarbon pollutants, leading to the enhancement of TPH degradation by stimulating co-metabolic processes (Correa-García et al. 2018; Hussain et al. 2018c). Some phenolic compounds in plant secondary metabolites such as salicylates and flavonoids could support the growth of some PAH-degrading microorganisms and enhance PAH metabolism (Thomas et al. 2017). For example, flavonoid compounds have been linked to the microbial degradation of some PAHs such as pyrene and phenanthrene (Técher et al. 2011) and, anthracene and phenanthrene (Garcés Mejía et al. 2018). Similarly, salicylate compounds may induce the expression of microbial degradative enzymes and favour co-metabolism of $\mathrm{B}[\mathrm{a}] \mathrm{P}$ (Rentz et al. 2005), phenanthrene and pyrene (Gao et al. 2010c). Nevertheless, the biodegradation pathways of co-metabolism of TPH in the presence of root-secreted compounds are not yet fully understood. Presumably, the stimulation of appropriate enzymatic pathways in the biodegradation of plant metabolites can enhance co-metabolic processes by supplying primary energy or carbon source favouring PAH degraders (Fletcher and Hegde 1995; Singer et al. 2003; Truskewycz et al. 2019). In this approach, plants are used as a biochemical approach to "inject" growth-substrates for microorganisms that can help them to express and extend their catabolic potential in the breakdown of recalcitrant organic 
contaminants in contaminated soils (Musilova et al. 2016). Because of the plethora of plant-derived PAH analogues, it is not surprising that the rhizosphere has been recognised as a "hot spot" containing a diverse population of PAH-degrading microorganisms, and it induces the genes encoding enzymes involved in PAH degradation (Garcés Mejía et al. 2018).

\subsubsection{Stimulation of microbial activities}

Plants exude a variety of signalling molecules (e.g., salicylates, flavonoids), carbon (e.g., organic acids, phenolic compounds), and nitrogen (e.g., amino acids) compounds into their rhizosphere, which all can selectively support microbial growth and activity (Correa-García et al. 2018; Kuiper et al. 2004). These compounds have been traditionally classified into water-soluble, low molecular weight (LMW) organic molecules, and insoluble, high molecular weight (HMW) organic polymers, which are broadly defined as root exudates (Martin et al. 2014; Meudec et al. 2006). Microorganisms can rapidly degrade LMW exudates such as carbohydrates, amino acids, and organic acids, while HMW organic polymers such as mucigel and root debris may have relatively longer biodegradation times (Gao et al. 2015; Jia et al. 2016; Ling et al. 2015). Apart from supplying carbon to soil microorganisms, there has been increasing evidence showing that root exudates, as chemical messengers, are of crucial importance in communicating and initiating biological and physical interactions between roots and soil microorganisms (Balasubramaniyam 2015; Grayston et al. 1997; Martin et al. 2014; Rohrbacher and St-Arnaud 2016). For example, coumarin exudation in the rhizosphere of Arabidopsis (rockcress) stimulated the presence and activity of pathogen resistance-inducing and plant growth-promoting rhizobacteria (Stringlis et al. 2018). Similarly, increased malic acid exudation in plants during drought can attract 
Bacillus subtilis, which is a beneficial bacteria that increases drought resistance by activating organic osmolyte secretion (Allard-Massicotte et al. 2016; GagnéBourque et al. 2016).

Generally, the presence of TPH compounds in soils can cause an increase in the secretion of plant root exudates, which are involved in root-soil contact as well as communication with soil organisms, acting as stress mediators (Balasubramaniyam 2015). Some associated microbes stimulated by the root exudates are able to degrade TPH compounds (Correa-García et al. 2018). For instance, using phenanthrene as a model hydrocarbon, Thomas et al. (2019) found that root exudates of ryegrass (Lolium perenne) favour the development of a consortium of phenanthrene-degraders owning specific functional traits at the genome level in the rhizosphere. Indeed, results from stable isotope probing (SIP) and metagenomics showed more genes were involved in aromatic compound metabolism in the rhizosphere of ryegrass in the contaminated soil compared to those in the corresponding bare soil (Thomas et al. 2019). Likewise, Sun et al. (2015) examined the effect of cowpea (Vigna unguiculata) root mucilage on soil microorganisms in phenanthrene-contaminated soil at the concentration of $100 \mathrm{mg} \mathrm{kg}^{-1}$ soil dry weight. The microbial profiles obtained from Denaturing Gradient Gel Electrophoresis (DGGE) suggested that root mucilage of cowpea selectively enriched the phenanthrene-degrading bacteria population in the rhizosphere, which led to significantly enhanced phenanthrene mineralization (82.7\%) in comparison to that in the control treatment without mucilage $(70 \%)$.

These findings indicate that root exudates can serve as a nutrition source, chemoattractant, and/or selective communication signal for many beneficial microorganisms. The pattern of root exudates varies on inter- and intra- species 
levels and actively modulates the microbial composition, diversity, and activity in the rhizosphere (Hussain et al. 2018c; Sasse et al. 2018), and may act as a useful criterion for the selection of plants in rhizoremediation of TPH-contaminated soils (Kawasaki et al. 2016; Sun et al. 2015).

\subsection{Factors affecting rhizoremediation of TPH}

The effective rhizodegradation of TPH requires, firstly, choosing the right plant and genotype (Dagher et al. 2019). In this regard, plant tolerance to TPH, root morphology, and root exudate profile should be taken into account (Correa-García et al. 2018). Recently, different types of plants have been used for the dissipation of TPH in soils, such as grasses (Kiamarsi et al. 2020; Steliga and Kluk 2020), legumes (Allamin et al. 2020; Hussain et al. 2019), agronomic crops (Baoune et al. 2019; Ghalamboran et al. 2020), ornamental plants (Cheng et al. 2019), and shrubs and trees (Anyasi and Atagana 2018; Pérez-Hernández et al. 2017). Generally, native plants show higher adaptation to contamination than introduced ones (Bell et al. 2014; Gaskin and Bentham 2010; Nedunuri et al. 2009), because of better interaction with the local beneficial soil microbiota (Bolan et al. 2013; Chowdhury et al. 2017). With respect to root morphology, plants with the ability to produce fibrous root systems such as grasses are often selected as they can harbor an abundance of microbial communities (Adam and Duncan 2002; Bolan et al. 2011; Fatima et al. 2015). Furthermore, the dense root system enhances soil aeration and water retention and can cover a large impacted surface area (Wenzel 2009). For example, Gaskin and Bentham (2010) assessed three Australian native grasses (Cymbopogon ambiguous, Brachiaria decumbens, and Microlaena stipoides) for their ability to stimulate degradation of aliphatic hydrocarbons from a mine soil artificially contaminated with diesel:oil $(60: 40)$ at $1 \%\left(10,000 \mathrm{mg} \mathrm{kg}^{-1}\right)$. Overall, the 
abundance of hydrocarbon-degrading microorganisms and extent of TPH degradation in the planted treatments for all grass species were significantly higher than the unplanted treatment during 100 days $(p<0.05)$. Of the three species, $C$. ambiguous showed the highest TPH degradation efficiency (88\%) and number of hydrocarbon-degrading microorganisms in the rhizosphere. The authors found a significantly negative correlation between residual TPH concentration and hydrocarbon-degrading microorganism population for all grass species. However, grasses typically do not root as deeply as trees. Therefore, when the pollutants exist in deeper soil layers, the use of deeper rooting plants such as trees may be a better alternative (Cook and Hesterberg 2013). Plants also produce a varying quantity and quality of root exudates resulting in substantial differences in the recruitment and promotion of rhizosphere microorganisms as well as contaminant desorption (LeFevre et al. 2013; Lundberg et al. 2012); consequently, this leads to different rhizoremediation rates among plant species (Figure 2A), even between closely related plant genotypes (Correa-García et al. 2018). For instance, Bell et al. (2014) found distinct microbial communities in the rhizosphere of 11 selected willow (Salix spp.) cultivars grown at a former petrochemical plant site, which were speculated to vary in their TPH-degradation potential in their rhizospheres (Bell et al. 2014).

Insert Figure 2 here

In addition to plant properties, environmental factors such as temperature and moisture also affect the rate of microbial degradation of TPH (Figure 2B). Although hydrocarbon biodegradation can naturally occur over a wide range of temperatures, the highest hydrocarbon degradation in the rhizosphere can be achieved between 15 and $25^{\circ} \mathrm{C}$ (Gaskin and Bentham 2005). Similarly, several physico-chemical properties of soil such as water availability, oxygen availability, organic matter, and 
nutritional factors, viz. nitrogen and phosphorus sources, and other nutrients affect rhizosphere microbial communities and their potential for TPH break down (Boopathy 2000). For example, soils with high contents of organic matter significantly reduced the biodegradation of TPH due to the strong sequestration of TPH by organic matter through hydrophobic interactions (Chefetz et al. 2000; Wei et al. 2017). However, elevated levels of soil organic matter was shown to enhance microbial activity, thereby facilitating TPH degradation in contaminated soils (Cheng et al. 2008; Nedunuri et al. 2009; Yang et al. 2011).

Another important factor affecting the rhizoremediation of TPH-polluted soils is the presence and activity of appropriate microorganisms, i.e., those which contain catabolic genes and/or produce biosurfactants (Fenibo et al. 2019). For complex hydrocarbon mixtures such as TPH, an association of mixed microbial strains (i.e., microbial consortia) is required for the mineralization of TPH compounds (Figure 2C), highlighting the importance of competent microbial structures and functions (dos Santos and Maranho 2018). For example, Thomas et al. (2019) found that the complete mineralization of phenanthrene was achieved through successive metabolic steps by the combined activity of taxonomically diverse co-occurring bacteria, whereby the initial activation steps were performed by Sphingomonadales taxa. In theory, the use of plants could enhance the performance of indigenous microorganisms for the removal of TPH in impacted soils (Garrido-Sanz et al. 2019). In practice, however, the efficiency of this remediation process could be partly considered as a matter of plant selection, because plant identity significantly shapes the rhizosphere microbial communities (Chowdhury et al. 2017; Dagher et al. 2019). Besides, the potential of autochthonous microorganisms are also influenced by 
several other factors such as pollutant characteristics (Chandra et al. 2013) and soil and environmental conditions (Beškoski et al. 2011; Varjani et al. 2015).

Last, but not the least, hydrocarbon characteristics and bioavailability play an essential role for successful rhizoremediation (Gkorezis et al. 2016). Due to the differences in physio-chemical properties, petroleum hydrocarbons do not degrade at the same rate (Figure 2D). Their biodegradability is controlled by carbon chain length and can be ranked in the following order (from high to low): linear alkanes branched alkanes - low molecular weight alkyl aromatics - monoaromatics - cyclic alkanes - polyaromatics - asphaltenes (Leahy and Colwell 1990; Tyagi et al. 2011). Furthermore, the rate of biodegradation of TPH depends on their concentrations and availability in soils (Khan et al. 2018). Typically, high molecular weight hydrocarbons with high octanol-water partitioning coefficient (Kow) values are considered less available for microbial attack and even the same compound can be degraded to different extents by the same microorganisms depending on the degree of weathering of hydrocarbons (Rojo-Nieto and Perales-Vargas-Machuca 2012; Varjani 2017). The $\mathrm{K}_{\mathrm{ow}}$ is defined as the ratio of concentrations of a chemical between two phases (octanol and water), representing the solubility of an organic compound in water. As the Kow increases, the aqueous solubility of the compounds decreases and their tendency to adsorb onto soil increases due to the increased hydrophobicity (Schwarzenbach et al. 2016).

In summary, rhizoremediation rates are driven by many interactive factors, viz. (a) plant characteristics, (b) soil and environmental conditions, (c) microbial properties, and (d) hydrocarbon characteristics. It is always recommended to consider all these factors (Figure 3) before deploying the remediation process at full implementation scale. 
Insert Figure 3 here

\section{Enhancement of rhizoremediation of petroleum hydrocarbon pollutants}

Apart from above-mentioned advantages, as with any environmental remediation technique, rhizoremediation also has limitations when it is chosen for rehabilitation of TPH-contaminated soils. For example, it is a slow process and only suitable as a long-term solution (dos Santos and Maranho 2018). However, the literature indicates that treating TPH-impacted soils with different amendments may enhance the rate of biodegradation. In spite of the wide diversity of the amendments, this approach can be broadly grouped into: (1) stimulation of existing plants and microorganisms capable of biodegradation (i.e., biostimulation), and (2) addition of plant growth-promoting and/or hydrocarbon-degrading and/or biosurfactantproducing microorganisms (i.e., bioaugmentation). The following subsections summarize the literature on these two amendment groups specifically in relation to rhizoremediation of TPH.

\subsection{Biostimulation-assisted rhizoremediation}

Although rhizoremediation occurs naturally, the presence of plants alone may have limited efficiency due to factors such as the environment and TPH bioavailability (Gkorezis et al. 2016). The principle behind biostimulation (addition of nutrient and carbon sources, electron acceptors, and other compounds to the contaminated soil system) as a method to increase TPH degradation relies on the establishment of a propitious environment for the metabolic activities of the naturally occurring degraders (Adams et al. 2015; Nanekar et al. 2015). Table 2 summarizes different biostimulation approaches used to stimulate the rhizoremediation of TPHcontaminated soils. 


\subsubsection{Addition of nutrient and carbon sources}

As all living organisms require some basic nutrients for their maintenance, growth, and reproduction, the interspecific competition between plants and microorganisms usually occurs in nutrient-limited soils (Kuzyakov and Xu 2013). Contaminated soils often have a low nutrient status and may hinder microbial and plant growth, which in turn decreases the dissipation of contaminants (dos Santos and Maranho 2018). Therefore, a balanced nutrition through fertilizer addition can reduce competition between plants and microorganisms and subsequently increase the rhizoremediation rates (Yavari et al. 2015). Moreover, nutrient addition can enhance plant survival in TPH-contaminated soils and foster productivity, thereby producing sufficient root biomass to encourage the development of microorganisms, which mainly cause the rhizodegradation of the contaminants (Huang et al. 2005; White et al. 2006).

Inorganic fertilizers (rich in $\mathrm{N}$ and $\mathrm{P}$ ) have been used to enhance degradation efficiency on TPH-contaminated soils (Hussain et al. 2018c). Rentz et al. (2003) grew $61 \mathrm{~cm}$ cuttings of hydrid poplar (Popilus deltoids $x$ nigra DN34) in TPHcontaminated soils in a greenhouse. The study investigated the impact of different fertilization regimes on root development and poplar growth over 97 days. The authors reported increased plant biomass and height and root density following the addition of a 10/5/5 NPK fertilizer applied at 1,121 kg ha ${ }^{-1}(112 \mathrm{~kg}-\mathrm{N}, 24.4 \mathrm{~kg}-\mathrm{P}$, $46.5 \mathrm{~kg}-\mathrm{K} \mathrm{ha}^{-1}$ ) compared to other treatments (e.g., nitrogen-fertilized alone, unfertilized). Few other controlled (net house and glasshouse) studies (Basumatary et al. 2012; Lin and Mendelssohn 1998; Merkl et al. 2005a) and field trials (Ayotamuno et al. 2009) showed increased plant biomass and degradation rates of TPH contaminated soil, with the addition of NPK fertilizers, and even with controlled- 
release inorganic fertilizer input (Cartmill et al. 2014) (Table 2). Redfield (1958) defined a microorganism stoichiometry of $\mathrm{C}_{106} \mathrm{~N}_{16} \mathrm{P}_{1} \mathrm{H}_{263} \mathrm{O}_{110}$, and therefore the ratio of $\mathrm{C}: \mathrm{N}: \mathrm{P}(106: 16: 1)$ was recommended for the estimation of how much nutrient amendment is needed to obtain the target biodegradation of contaminants (Hussain et al. 2018c). An optimal C:N:P ratio, however, has been found plant- and sitespecific (Kirkpatrick et al. 2006). For example, a C:N:P ratio of 100:2:0.2 was recommended for rhizoremediation of soil (containing significant concentrations of total nitrogen and phosphorus) contaminated by aged petroleum sludge $(5 \%, \mathrm{w} / \mathrm{w})$ using bermuda grass (Cynodon dactylon) and tall fescue (Festuce arundinacea) (Hutchinson et al. 2001). In another study, by adding $\mathrm{NH}_{4} \mathrm{NO}_{3}$ and $\mathrm{K}_{2} \mathrm{HPO}_{4}$ to achieve a C:N:P ratio of 100:10:1 in composted TPH-contaminated soil $(2,541 \mathrm{mg}$ $\mathrm{kg}^{-1}$ dry soil), the remediation process using sesbania pea (Sesbania cannabina) was shown to be effective, which decreased TPH concentration to $673 \mathrm{mg} \mathrm{kg}^{-1}$ at the $90^{\text {th }}$ day (Maqbool et al. 2012).

Apart from inorganic fertilizers, various organic amendments generated from municipalities, industrial processes, animal husbandry and bulking agents have been applied to stimulate rhizoremediation efficiency (Park et al. 2011; Robichaud et al. 2019; Zhang et al. 2012). Waste products such as animal manure, compost, and sewage sludge provide multiple benefits in remediation approaches. These contain high loads of active microorganisms, nutrients, and organic carbon, which improve soil quality, promote plant growth, stimulate soil microbial populations, and enhance their metabolic capacity (Agarry et al. 2014; Park et al. 2011). Hence, by recycling organic amendments in contaminated sites, such materials may provide a sustainable avenue for TPH remediation. White Jr et al. (2003) investigated the effect of broiler litter, peppermill sludge, hardwood sawdust, and inorganic fertilizer 
on plant performance in $\mathrm{TPH}$-contaminated soil at the contamination level of $7.9 \%$ (w/w). Additionally, the impact on TPH degradation was also evaluated. The soil amendments showed improved plant performance in terms of biomass production and germination compared to an unamended (control) treatment. When averaged across each plant species studied, the TPH content in the soil was $7.88,7.93,7.12$, 6.61 , and $6.01 \%$ for the unamended control, peppermill sludge, inorganic fertilizer, sawdust, and broiler litter, respectively. The greater reduction in TPH levels in broiler litter-amended treatment compared to the other soil amendments resulted from increased soil nitrogen $(\mathrm{N})$ and plant available phosphorus $(\mathrm{P})$ in the TPHcontaminated soil (White Jr et al. 2003). Similarly, in a study by Saum et al. (2018), the addition of compost at $5 \%(\mathrm{w} / \mathrm{w})$ to soil contaminated by automobile motor oil at the concentration of $2 \%(\mathrm{w} / \mathrm{w})$ showed the greatest extent $(44 \%$ of the light hydrocarbon fraction) of oil degradation in the rhizosphere of native mesquite shrubs (Prosopis articulate). Zhang et al. (2012) reported that amendments with different dosages of sewage sludge and cattle manure increased the removal efficiency of PAHs in the presence of alfalfa and PAH-degraders (Bacillus sp. and Flavobacterium sp.) from $35.5 \%$ to $44.9 \%$ and $25.5 \%$ to $42.3 \%$, respectively, whilst the unamended (control) only obtained the removal rate of $5.6 \%$. More surprisingly, the amendment with mixed organic wastes (banana skin, brewery spent grain, and spent mushroom compost) rapidly increased the rhizoremediation efficiency with physic nut (Jatropha curcas) up to $89.6 \%$ and $96.6 \%$ in $2.5 \%$ and $1 \%$ lubricating oilcontaminated soils, respectively (Agamuthu et al. 2010). Likewise, Wang et al. (2012) also reported that compost application significantly stimulated pyrene degradation in the rhizosphere of ryegrass (Lolium perenne) and alfalfa up to 9899\% and 97-99\%, respectively. 
Biochar refers to carbonaceous, fine-grained, porous materials produced from slow pyrolysis (heating in the oxygen-limited conditions) of organic material (Cantrell et al. 2012). Biochar originates from a variety of feedstock materials, which may include agricultural and forestry by-products, animal/poultry wastes, and sewage sludge or slurries (Wiszniewska et al. 2016). The addition of biochar to degraded soils can not only improve plant growth through enhancing soil fertility, nutrient retention, and oxygen supply, but also promote microbial growth and biomass (De Tender et al. 2016; Liu et al. 2017a; Song et al. 2016), which in turn can stimulate rhizoremediation efficiency (Barati et al. 2018; Zhen et al. 2019). Moreover, biochar can strongly absorb residual TPH and metabolites to provide a slow-release TPH source for continued microbial degradation (Qin et al. 2013). For example, Chirakkara and Reddy (2015) found that PAH degradation by sunflower (Helianthus annuus) and oat (Avena sativa) was improved with pine wood biochar amendment (50 $\mathrm{g} \mathrm{kg}^{-1}$ soil) in soils co-contaminated with PAHs and heavy metals. Similarly, biochar was proven as a useful amendment for enhancing TPH rhizodegradation at different pollution levels $(4,6$, and $8 \%, w / w)$ with barley (Hordum vulgare) and oat plants (Barati et al. 2017). Particularly, plant growth, microbial respiration, and TPH reduction rates were significantly higher in a biochar treatment than a non-biochar treatment, indicating that biochar stimulated the plant growth and microbial activity in the polluted soils. However, with respect to additional effects, biochar was reported to cause a likely decrease in $\mathrm{N}$ availability to plants, which can inhibit plant growth and consequently reduce rhizoremediation efficiency (Saum et al. 2018). This result was in agreement with a previous investigation by Han et al. (2016) where the application of biochar hindered TPH degradation in the rhizosphere of ryegrass (Lolium perenne L.). Although bulking agents (e.g., wood chips, hay, 
brans, straw, and bark) and forced aeration such as tilling have been rarely mentioned in the literature as the sole supplement, these amendments can improve the rhizoremediation rate of TPH by stimulating the microbial activity via increasing the soil porosity and oxygen diffusion (Dhote et al. 2017; Huang et al. 2005; Nanekar et al. 2015).

However, a disadvantage of adding solid organic waste by-products to TPHcontaminated soils is that the solubility or bioavailability of TPH compounds might not be improved, and they might well be decreased by such treatments due to an increased affinity of the contaminants to the soils (Beckingham and Ghosh 2017; Saum et al. 2018; Wiszniewska et al. 2016). An increase in the solubility and subsequently the bioavailability of petroleum hydrocarbons is thus considered as the key step in enhancing the efficiency of TPH rhizoremediation (Almansoory et al. 2015; Liao et al. 2016; Liu et al. 2013).

Insert Table 2 here

\subsubsection{Addition of surfactants and surfactant-like compounds}

Surfactants are a group of amphiphilic chemicals, which simultaneously consist of both hydrophilic and hydrophobic parts in their molecular structures (Möbius et al. 2001). This unique structure of surfactants can enhance water solubility of soil contaminants, especially in cases of hydrophobic organic compounds such as TPH and PAHs, thereby facilitating their assimilation by microorganisms (Kuyukina et al. 2005; Mao et al. 2015). A variety of surfactants (e.g., anionic, cationic, zwitterionic, and non-ionic) from both synthetic and natural sources have been tested and/or utilized for enhancing rhizoremediation of TPH (Agnello et al. 2014). 
Cheng et al. (2008) examined the effect of Tween 80 on PAH removal from spiked soils vegetated with tall wheatgrass (Agropyron elongatum), and they noticed a positive effect of the synthetic surfactant on pyrene removal. The increase in pyrene removal was probably due to the capacity of the surfactant to solubilize and desorb $\mathrm{TPH}$, which enhanced the bioavailability of the contaminants. Similarly, Triton X100 decreased the residual concentrations of phenanthrene in bulk soil whilst increasing it in the rhizosphere soil of $M$. sativa (Wu et al. 2008). The authors hypothesized that the surfactant likely altered the desorption of the contaminant, enhancing its mobility and transportation from the bulk soil to the rhizosphere soil. In this study, however, Triton X100 application of $0.1 \%(\mathrm{w} / \mathrm{w})$ in soil decreased $M$. sativa shoot and root biomass as well as soil mycorrhizal fungi population. Since many synthetic surfactants, which have been trialled for stimulating degradation of TPH and PAHs in soils, are toxic to microorganisms and plants and can persist in the soils for long time, biologically produced surfactants (biosurfactants) or other compounds with similar properties and less toxicity are required for improving soil remediation (Agnello et al. 2014; Betancur-Corredor et al. 2015; Staninska-Pięta et al. 2019).

Almansoory et al. (2015) stated that the inclusion of a biosurfactant derived from the bacterium Serratia marcescens at a concentration of $10 \%(\mathrm{w} / \mathrm{w})$ with Mexican primrose-willow (Ludwigia octovalvis) removed a significant amount (up to 93.5\%) of TPH in the studied soil. More interestingly, Benson et al. (2017) compared the effect of lipopeptide-type biosurfactant and a synthetic surfactant (sodium dodecyl sulfate, SDS) amendment at $2 \%(\mathrm{w} / \mathrm{w})$ on the degradation of petroleum hydrocarbon in a TPH-contaminated soil (the initial concentration of $861.3 \mu \mathrm{g} \mathrm{kg}^{-1}$ ) using alfalfa. The results showed that with the biosurfactant amendment, the plant biomass and hydrocarbon degradation percentage (204.6 g pot ${ }^{-1}$ and $65.6 \%$, respectively) were 
higher than those with the SDS amendment (171.2 $\mathrm{g} \mathrm{pot}^{-1}$ and $32.7 \%$, respectively). Similarly, Liao et al. (2016) compared the ability of removing TPH from soil vegetated with maize (Zea mays. L) by two biosurfactants (rhamnolipid and soybean lecithin) and a synthetic surfactant (Tween 80). The treatments with rhamnolipid or soybean lectin significantly increased the soil microbial population compared to those in the Tween 80 and unamended (control) treatments, indicating that the degradable surfactants had a promoting effect on the microbial population. In addition, the removal efficiencies of TPH in the treatments with rhamnolipid, soybean lecithin, Tween 80 , and the control were $62,58,47$, and $50 \%$, respectively, suggesting that the addition of the two biosurfactants enhanced the degradation of TPH from soil (Liao et al. 2016). These studies indicated that biosurfactantamended rhizoremediation can be a useful biotechnological approach for the remediation of TPH-polluted soils.

Nevertheless, the application of biosurfactants to environmental remediation in large amounts is challenging due to the high cost of these compounds. Consequently, only a few biosurfactants (e.g., surfactin and rhamnolipids) have been applied to remedy TPH-impacted soils (Liu et al. 2017b; Santos et al. 2016). Fortunately, a range of organisms produce compounds that have surfactant-like properties. Sapononics are a group of compounds obtained primarily from plants and have properties of being able to enhance solubilisation of hydrophobic compounds. The term 'Saponin' is derived from the group term 'sapo', which is interpreted as meaning soap (Vincken et al. 2007). In general, saponin compounds are not referred to as surfactants, because they do not have the typical surfactant structure (see Table 3). The saponins studied to date belong to the chemical groups of triterpenes and steroid glycosides (Muffler et al. 2011; Sobolewska et al. 2016). 
Insert Table 3 here

About 28 different plant orders have been identified that can produce compounds with soap-like structures, and they consist of 273 different plant species (Vincken et al. 2007). For the purpose of TPH and PAH remediation, the genus of Sapandus has been investigated extensively, owing to the availability and biomass of these species. Although many species of Sapindus are believed to have the ability to produce compounds having soap-like structures, the two species that have received the greatest attention are Sapindus saponaria and Sapindus mukorossi (Lozsan et al. 2017; Zhou et al. 2013).

A number of bioremediation studies showed excellent solubilisation potential of hydrophobic organic compounds such as TPH using saponins as an amendment. For example, Kobayashi et al. (2012) applied 2,500 - 10,000 mg/L saponin solutions derived from quillaja bark to extract pyrene from two individual soil types containing different soil organic carbon (SOC) contents (high and low). Both soils were spiked with $83.9 \mathrm{mg} \mathrm{kg}^{-1}$ pyrene. At $10,000 \mathrm{mg} / \mathrm{L}$ saponin, the extraction of pyrene ranged between 3 and $53 \%$ in spiked soils with high and low SOC, respectively. Moreover, the effect of saponin on PAH biodegradation was also examined using a pure culture of a PAH degrader (Sphinogomonas sp.) at the initial cell concentration of $10^{8} \mathrm{CFU} \mathrm{mL} \mathrm{m}^{-1}$. The addition of saponin resulted in the enhanced biodegradation of pyrene compared to the control (without saponin) during a 60hour incubation regardless of concentrations. Similarly, Zhou et al. (2013) also reported that saponin extracted from the fruit pericarps of Chinese soapberry (Sapindus mukorossi) could remove up to $87.4 \%$ of phenanthrene from a spiked soil. More surprisingly, the saponin from quillaja bark showed the highest efficiency in removing phenanthrene from spiked soils in comparison to other synthetic and 
bio surfactants (SDS and rhamnolipid, respectively) (Urum et al. 2006). These findings indicated that saponins have potential applications in enhancing solubilisation and biodegradation of hydrocarbon compounds. Saponins could reduce the surface tension of TPH compounds, which would enable the degradation of these compounds by microorganisms. Besides, saponins may attach to microbial cell surfaces and increase the modification of cell hydrophobicity of microorganisms (Liu et al. 2017b). Taken together, the addition of saponins could enhance the mass transfer of the contaminants to the microorganisms and may have significant effects on the rhizoremediation of TPH. However, almost all studies about these surfactantlike compounds were conducted in the absence of plant species. Further investigations are therefore necessary to provide useful information for the selection of types and concentrations of saponins used to remove TPH from contaminated soils in the rhizoremediation approach involving plants, especially those that store saponins in roots (Faizal and Geelen 2013).

\section{2. Bioaugmentation-assisted rhizoremediation}

Petroleum hydrocarbons can have negative impacts on soil microbial composition and activity (e.g., low species diversity as well as reduced biomass). Since soil microorganisms play an important role in the growth of plants, the biological disturbance can adversely affect the development of plants. In addition, many plants are sensitive to $\mathrm{TPH}$; even tolerant species cannot grow well or support their microbiota (dos Santos and Maranho 2018; Hussain et al. 2018c; Nardeli et al. 2016). Given that rhizoremediation relies on the symbiotic relationship between soil microorganisms and plants, any detrimental influence on plants and/or microorganisms would have direct and indirect consequences, resulting in the inhibition of biodegradation of pollutants (Razavi et al. 2016). 
Bioaugmentation is defined as the enhancement of performance of microbial communities through the introduction of microbial populations with specific catabolic activities in adequate numbers (Abdulsalam et al. 2011; Paliwal et al. 2012). In other words, with regards to TPH rhizoremediation, an external source of hydrocarbondegrading and/or plant growth-promoting and/or surfactant-producing microorganisms is added to the existing microbial population in the rhizosphere of host plants to enhance the contaminant degradation rates (Glick 2010). This approach was proposed for TPH-contaminated soils to overcome the abovementioned stresses to plants and their associated microorganisms, and enable a realistic application of rhizoremediation technology (Gurska et al. 2009; Huang et al. 2005). Table 4 summarizes different bioaugmentation approaches used to stimulate the rhizoremediation of TPH-contaminated soils.

\subsubsection{Addition of biodegrading microorganisms}

Generally, an individual microbial species has specific enzymatic ability and preference for a limited range of hydrocarbon substrates (dos Santos and Maranho 2018). Therefore, it has been widely accepted that the biodegradation of complex organic compounds such as TPH typically requires the concerted efforts of several groups of degraders (i.e., microbial consortia) to have a better potential in the rhizoremediation process (Kuiper et al. 2004). As hydrocarbon-contaminated soils usually have low microbial diversity, the introduction of strains or consortia of microorganisms with desired catabolic activities is considered as a technique for increasing TPH removal (Cai et al. 2016; Pacwa-Płociniczak et al. 2019).

Although some successful examples on the application of a single microbial strain in rhizoremediation are available, strong evidence shows that the bioaugmentation 
with a consortia is generally more efficient than individual strains for TPH degradation (Anza et al. 2019; Dealtry et al. 2018; Rodriguez-Campos et al. 2019). Some of the desired properties for the microbial consortia for rhizoremediation that have been recommended include being able to handle abiotic stress, particularly contaminant stress, and being able to grow to the desired density under stressful conditions (Calvo et al. 2014; Yang et al. 2009). When considering the application of bioaugmentation to a TPH-contaminated site, two approaches can be used: (1) an allochthonous, defined as the inoculation of a foreign consortium isolated from another TPH-contaminated sites (rhizosphere and/or non-rhizosphere), or (2) an autochthonous, defined as an indigenous consortium enriched from the contaminated soil (rhizosphere and/or non-rhizosphere) and cultivated with hydrocarbons as the sole carbon source and then re-inoculated (Gkorezis et al. 2016; Ueno et al. 2007). For instance, the efficiency of TPH rhizoremediation by perennial ryegrass was investigated by Chuluun et al. (2014) using a designed microbial consortium consisting of ten bacterial strains ( $R$. erythropolis, $C$. variabile strain DCM44702, N. subarcticum, A. xylosooxidans strain ZH4, P. putida strain PCM2153, P. citronellolis strain FX6, R. lindaniclasticus, S. maltophilia strain KNUC605, E. cloacae, and C. freundii strain UMS5/10) isolated from petroleumcontaminated soils. The main aim of this research was to compare the effectiveness of different biological approaches including bioaugmentation alone, rhizoremediation alone, and bioaugmented-rhizoremediation together in a model soil spiked with $50 \mathrm{~g}$ diesel oil kg-1 soil. The study demonstrated that a concomitant use of the hydrocarbon-degrading bacterial consortium and the perennial ryegrass for remediation of diesel-contaminated soil had the highest TPH removal rate over a 90 -day period (57.3\%, which was $7.3 \%$ and $5.3 \%$ more efficient than the 
rhizoremediation alone and the bioaugmentation alone, respectively). Similar results were also shown in a study reported by Ebadi et al. (2018) where the use of the salinity-tolerant Pseudomonas aeruginosa consortium (which was a mixture of four strains of hydrocarbon-degrading bacteria, namely Ochrobactrum intermedium R2, Microbacterium oryzae R4, Pseudomonas sp. R7, and Alcaligenes faecalis R8 at 1:1:1:1 ratio) in conjunction with the halophyte salicornia (Salicornia persica) or tall fescue boosted the degradation of TPH up to $17 \%$. Interestingly, the specific combination between S. persica and the bioaugmentation resulted in an increase of the soil dehydrogenase activity and abundance of bacteria, which altogether led to the reduction of phytotoxicity of TPH in a saline soil. Similarly, the introduction of a exogenous hydrocarbon-degrading consortia (M10), composed of Rhodoccocus equi, Enterobater sp., Acinetobacter calcoaceticus, Comamonas sp., and Pseudomonas alcaligenes, to a contaminated soil (up to $24,000 \mathrm{mg}$ diesel oil kg-1 soil) growing rapeseed (Brassica napus) was found to increase the plant's root length and biomass. This mechanism indicated that B.napus and the M10 bacterial consortium could be suitable candidates for a long-term rhizoremediation approach (Graj et al. 2013). More recently, Kiamarsi et al. (2020) introduced a consortium of hydrocarbon-degrading bacteria, including five strains (Pseudomonas resinovorans, Plantibacter auratus, Bacillus subtilis, Staphylococcus pasteuri, and Bacillus atrophaeus), in the rhizosphere of the vetiver grass plant (Vetiveria zizanioides L.) growing in soils contaminated with various oil concentrations $(0,2$, $4,6,8,10$, and $12 \%, w / w)$. The authors found that the inoculation of bacterial consortia enhanced the plant growth as well as hydrocarbon degradation during the 120 days of the study. Particularly, the results revealed that TPH degradation was in the range of $57.5-84.6 \%$ in the presence of plant and inoculated consortia, which 
was higher than that in the presence of vetiver alone $(47-77 \%)$. Thus, the combination of plants and hydrocarbon-degrading microorganisms could be used effectively for cleaning TPH-contaminated soils.

Although exogenous hydrocarbon-degrading microorganisms have been used in some studies for achieving bioaugmented-rhizoremediation of contaminants, this application cannot guarantee the adaptability and competitiveness of the inoculum since native microorganisms are well-adapted to particular rhizosphere conditions (Gkorezis et al. 2016). Moreover, the use of non-native microorganisms is not usually encouraged for regulatory reasons as it may cause unknown or unexpected consequences such as causing or carrying disease, and changing endemic microbial structure and function (Xia et al. 2017). Therefore, several studies have been conducted on the use of indigenous consortia at the rhizosphere level (Liu et al. 2013). For example, Escalante-Espinosa et al. (2005) studied Cyperus laxus Lam. inoculated with rhizosphere bacteria and fungi previously isolated from a C.laxus rhizosphere, where they exhibited efficient hydrocarbon degradation capacity. The designed microbial consortium was composed of ten bacterial strains (Bacillus cereus, Pseudomonas sp., Gordonia rubripertincta, Kocuria rosea, Arthrobacter oxydans, Bacillus subtilis A, Bacillus subtilis B, Micrococcus luteus, and two unidentified strains) and three fungal strains (Penicillium janthinellum, Aspergillus carneus, and Aspergillus terreus). After 180 days, TPH rhizoremediation efficiency was $90,85,70$, and $76 \%$ for plants inoculated with the microbial consortium, plants not inoculated, a control without plants nor the microbial consortium, and a control with the microbial consortium without plants, respectively, suggesting the beneficial effect of the added microbial inoculum in a rhizoremediation approach (Escalante-Espinosa et al. 2005). Likewise, the 
exploitation of hydrocarbon-degrading and plant growth-promoting indigenous bacteria enhanced the phytoremediation process in a mixed-contaminated (nickel + copper + alkylaromatic hydrocarbons) soil (Franchi et al. 2016). In this study, the metal-tolerant bacteria, including SMV187.1, SMV189.20, SMV196.26, SMV197.30, SMV201.7, and SMV206.42, isolated from a polluted site, were shown to enhance both the shoot and root biomass and metal uptake potential of sunflower (Helianthus annuus) grown in the above-mentioned soil pre-treated with a land-farming process. Additionally, this approach also stimulated the degradation of alkylaromatic hydrocarbons (up to $80 \%$ ), as confirmed by mass spectrometry analysis. The authors concluded that the three-step approach (land-farming, bioaugmentation, and rhizoremediation) could be applied as a fully biological process to remove simultaneously organic and inorganic contaminants.

In addition to degrading TPH per se, it has been suggested that some microorganisms may make the relatively insoluble contaminant compounds more soluble, and hence bioavailable. The capacity to improve TPH bioavailability is likely to exist for only a limited number of bacteria that contain hydrophobic external surfaces (Glick 2010). For example, Kotoky and Pandey (2019) found that two bacterial isolates, namely Bacillus flexus S1I26 and Paenibacillus sp. S1I8, from petroleum contaminated sites showed $\mathrm{B}[\mathrm{a}] \mathrm{P}$-degrading and surfactin-producing abilities. The introduction of these bacteria in the rhizoremediation of $\mathrm{B}[\mathrm{a}] \mathrm{P}$ contaminated soil (5 mg B[a]P kg-1 soil) with chinaberry plant (Melia azadirachta) in a pot experiment showed higher rates of degradation compared to that in the bulk soil. Particularly, after application of S1I26 and S1/8, the rate of degradation was found to be much higher ( 87.42 and $86.08 \%$, respectively) in the rhizosphere of the plant than in the bulk soil $(68.22 \%)$. Similar results were also observed by Ram et 
al. (2019), where the introduction of oil-degrading and rhamnolipid-producing bacteria Shewanella seohaensis BS18 obtained from a hydrocarbon contaminated site enhanced the remediation of TPH by the use of vetiver grass (Chrysopogon zizanoises L.). Ram and co-workers (2019) mentioned that rhamnolipid application at a concentration of $2 \%(\mathrm{w} / \mathrm{w})$ in soil amended with $2 \%(\mathrm{w} / \mathrm{w})$ diesel oil along with bioaugmentation using BS18 (6.4 Log CFU g$^{-1}$ soil) had the highest plant biomass and hydrocarbon-degrading bacterial population compared to other treatments. Not surprisingly, this combined approach recorded much higher TPH removal in soil (up to around $50 \%$ ) compared to other treatments such as the use of plant or bioaugmentation alone. Both biosurfactants (rhamnolipid and surfactin) produced by inoculated bacterial strains in these investigations possessed excellent emulsifying activity with a variety of petroleum hydrocarbons and reduced the interfacial tension of water/oil systems, which increased the contact area between bacteria and hydrocarbon droplets and the solubility of non-aqueous phase of liquids.

Insert Table 4 here

\subsubsection{Addition of plant growth-promoting microorganisms}

The presence of TPH in soils is capable of causing negative effects in plants in various growth and developmental stages, mainly because of its potential to induce an oxidative stress (Khan et al. 2013; Nardeli et al. 2016). Huang et al. (2005) stated that in the rhizoremediation technique, unless the plant species is able to grow and produce enough root biomass for the development of soil microorganisms in a TPHcontaminated site, the plant is likely to hinder the degradation of the contaminant. Fortunately, the above stress can be reduced by using hydrocarbon-tolerant 
microorganisms with plant growth-promoting (PGP) traits (Hou et al. 2015). The PGP microorganisms perform several functions, such as phosphate solubilisation, production of phytohormones (e.g., cytokinins CK, gibberellins GA, and indole-3acetic acid IAA) and siderophores, nitrogen fixation, and 1-aminocyclopropane-1carboxylic acid (ACC) deaminase synthesis (Płociniczak et al. 2017). As a result, these microorganisms have been used as inocula to boost plant growth, reduce contaminant-induced stress, and stimulate degradation of TPH by rhizosphere microorganisms (Kuo et al. 2014; Xia et al. 2020; Xun et al. 2015).

Inoculation of a bacterial consortium consisting of five strains including Pseudomonas sp. strain PFS1 and BSS3B2, Serratia proteamaculans strain S1BD1, Alcaligenes sp. strain PKS1, and Bacillus sp. strain PSS2 had a significant positive effect on the biomass production of salt-tolerant saltgrass (Distichlis spicata) (4-fold and 6.6-fold in sterilized and unsterilized soils compared to noninoculated treatment, respectively) in a saline TPH-contaminated soil under greenhouse conditions (Xia et al. 2020). In this study, bacterial strains were selected exhibiting different plant growth promoting characteristics as previously described in literature. The specific plant growth-promoting characteristics included the production of the plant hormone IAA by Pseudomonas genera, phosphate solubilisation by Alcaligenes genera, siderophore production by Bacillus genera, and fixation of free nitrogen and siderophore production by Serratia proteamaculans. Teng et al. (2011) introduced a rhizobial strain, Rhizobium meliloti (strain ACCC 17519), to alfalfa, and the inoculation was shown to enhance soil microbial activity, in general, and hydrocarbon-degrading rhizosphere microorganisms, in particular; hence, the plant biomass production in agricultural TPH-contaminated soil was increased. The production of plant hormones is 
considered as the major means of PGP microorganisms to assist host plants to overcome contaminant-induced stress responses (Werner et al. 2001). Nevertheless, many of PGP microorganisms are able to synthesize the enzyme ACC deaminase, which alleviates the levels of the stress hormone ethylene in a developing plant (ethylene is produced because of the presence of petroleum hydrocarbons) (Asghar et al. 2017; Rezvani Borujeni et al. 2018). Recently, Płociniczak et al. (2017) assessed the effectiveness of inoculation with the strain Rhodococcus erythropolis CD 106 on the rhizoremediation of an aged hydrocarbonimpacted (approx. 1\% TPH) soil using ryegrass. The authors found that the $R$. erythropolis strain showed ACC deaminase activity, which remarkably increased the fresh weight of the ryegrass and the removal of TPH in planted soil after 210 days, the time of the experiment. In particular, the shoot and root fresh biomass of the plants inoculated with CD 106 were enhanced by 49 and 30\%, respectively, compared to the non-inoculated treatment. The planted soil inoculated with the CD 106 showed the highest TPH remediation efficiency (31.2\%), whereas the results obtained for ryegrass without the inoculation and the CD 106 alone were comparable (16.8 and $18.7 \%$, respectively). In addition to ACC deaminase activity, R. erythropolis also has expressed the ability to degrade petroleum hydrocarbons and/or produce biosurfactants. Taken all together, the $R$. erythropolis strain in combination with ryegrass could be regarded as an effective approach to increase the rhizoremediation efficiency of TPH-polluted soils (Płociniczak et al. 2017). Similarly, Hong et al. (2011) mentioned that the ACC deaminase activity and siderophore production, due to the inoculation of a rhizobacterium Gordonia sp. S2RP-17, had a positive correlation with TPH degradation in the rhizosphere of corn 
(Zea mays). In this case, a TPH removal efficiency of up to $95.8 \%$ was obtained in a 46-day period under greenhouse conditions (Hong et al. 2011).

Similar to bacteria, AMF can also result in quantitative and qualitative changes regarding root exudation and soil microbial communities in the rhizosphere (Gerhardt et al. 2009; Iffis et al. 2017). Hence the introduction of AMF could enhance rhizoremediation of TPH-contaminated soils (Alarcón et al. 2008; HernándezOrtega et al. 2012; Kuo et al. 2014). For example, Kuo et al. (2014) investigated the effect of rhizoremediation in soils contaminated with heavy crude oil $(10 \%, w / w)$ using five different plant species (Vetiveria zizanioides, Bidens pilosa, Chloris barbata, Eleusine indica, and Imperata cylindrica) infected by an AMF (Glomus mosseae). The authors found that only V. zizanioides, B. pilosa, and E. indica could take up the G. mosseae. After 64 days, the AMF inoculation onto root surfaces of the plant species of $V$. zizanioides and B. pilosa was helpful to promote plant growth and TPH degradation in the polluted soils, whereas the inoculation exhibited a negative impact for the plant species $E$. indica compared to the systems without inoculation. The authors concluded that plants should be selected to match sitespecific conditions and be able to be inoculated easily by mycorrhiza fungi. Similarly, the addition of AMF in combination with hydrocarbon-degrading and/or PGP microorganisms also showed some positive results with respect to plant growth performance and TPH removal rates (Alarcón et al. 2008; Dong et al. 2014; Xun et al. 2015). For example, Dong and co-workers (2014) observed increased soil microbial activity, and TPH removal rate in the rhizosphere of oat (Table 4). They concluded that the increased production of "antioxidant enzyme" by the coinoculation treatment alleviated the adverse impact of petroleum hydrocarbons to 
oat, and the treatment could, therefore, be considered as a promising strategy for enhancing the remediation efficiency of TPH-impacted soils.

Taking the concept of bioaugmentation one step further, a few studies have tried to use genetically modified microorganisms or synthetic microbial communities for rhizoremediation (Jussila et al. 2007; Pizarro-Tobías et al. 2015). However, both the above approaches are facing many technical and legislative issues and potential risks to humans and other ecological receptors (Correa-García et al. 2018; Kritikos 2018). The use of naturally occurring and high performing microbial communities, which could eliminate the potential risks to human and ecological health, and future investigations for testing the compatibility of an individual strain with other strains, could be better alternative solutions.

It is recommended that for individual strain application, the inoculum density plays an essential role in the success of bioaugmentation process, as it can affect the activity and structure of soil microbial communities following the inoculation (Asghar et al. 2017; Xun et al. 2015). For instance, inoculation with the highest concentration (10 ${ }^{8}$ cell $\mathrm{cm}^{-3}$ soil) of the alkane-degrading Pantoea $\mathrm{sp}$. to perennial ryegrass resulted in maximum plant biomass, diesel degradation, bacterial abundance as well as CYP153 alkane hydroxylase gene expression compared to other treatments (e.g., $10^{5}, 10^{6}, 10^{7}$ cell $\mathrm{cm}^{-3}$ soil) (Shabir et al. 2016). Despite the reduction of TPH concentration reported in numerous bioaugmented-rhizoremediation studies, it is still unclear whether the enhanced TPH degradation was carried out by the introduced microorganisms or any other entity existing in the complex soil system. This doubt might arise due to the fact that the microbial inoculation might serve as bio-fertilizers for stimulating the autochthonous microorganisms' performance, when they are not able to survive in a contaminated soil (Shahi et al. 2016). As a 
result, a successful application of inoculum should be confirmed by monitoring the survival of the introduced microorganisms and soil microbial communities in addition to measuring the residual TPH concentrations in the concerned soil (Zhao et al. 2016). Further enzymatic pathways can be studied using metaproteomic and metabolomics approaches (Bargiela et al. 2015).

Despite the proven effectiveness of biostimulation and bioaugmentation for enhancing TPH rhizoremediation, in many instances the simultaneous application of these approaches has resulted in additional improvement of plant growth, soil microbial activity, and consequently TPH biodegradation (Benson et al. 2017; Dhote et al. 2017; Huang et al. 2005; Hussain et al. 2018a; Kogbara et al. 2016; Ram et al. 2019; Shahzad et al. 2016; Wenzel 2009). For example, Benson et al. (2017) examined the effect of application of lipopeptide-type biosurfactant at the concentration of $2 \%(\mathrm{w} / \mathrm{w})$ along with inoculation with ACC deaminase-producing bacteria Bacillus sp. PVMX4 (inoculation load $>10^{9} \mathrm{CFU} \mathrm{mL}{ }^{-1}$ ) on alfalfa growth and hydrocarbon degradation in a TPH-contaminated soil (initial hydrocarbon concentration $861.3 \mathrm{\mu g} \mathrm{kg}^{-1}$ ) under growth chamber conditions. The authors reported the additive effect of the combination (T1) compared to the bacterial inoculation alone (T2) or the biosurfactant alone (T3) regarding plant growth and TPH removal. In particular, the plant biomass in T1, T2, and T3 treatments were $212.4,161.2$, and $204.6 \mathrm{~g} \mathrm{pot}^{-1}$, respectively. Similarly, the hydrocarbon degradation percentage was $76.5 \%$ in the $\mathrm{T} 1$ treatment, which was higher than in $\mathrm{T} 2$ and $\mathrm{T} 3$ treatments (28.9 and $6.6 \%$, respectively). Most recently, similar results were observed by Ram et al. (2019), where the application of a rhamnolipid-type biosurfactant or bioaugmentation alone for rhizoremediation of hydrocarboncontaminated soil by vetiver grass was reported less effective than the combined 
use of biosurfactant and bioaugmentation. Particularly, the combined treatment yielded the highest plant dry biomass $\left(8.3 \mathrm{~g} \mathrm{pot}^{-1}\right)$ and hydrocarbon-degrading bacterial population (6.4 Log CFU g ${ }^{-1}$ dry soil), and the lowest TPH concentration in soil (approx. $2 \mathrm{mg} \mathrm{g}^{-1}$ dry soil) after 135 days of the study. More interestingly, the inoculation of a microbial consortia suspension, which consisted of four dieseldegrading bacterial strains (Pseudomonas poae, Actinobacter bouvetii, Stenotrophomonas rhizophila, and Pseudomonas rhizosphaerae), in combination with compost $(5 \%, v / v)$ and biochar $(5 \%, v / v)$ showed the highest TPH removal efficiency $(>80 \%)$ by ryegrass in the rhizoremediation of crude oil spiked soil $(3.4 \%$, w/w) (Hussain et al. 2018a). In agreement with other researchers, the authors recommended that this combination opened a new green approach in which biostimulation and bioaugmentation could be used effectively together for the effective rhizoremediation of TPH-contaminated soils.

\section{Rhizoremediation of TPH at field scale: pitfalls and potential}

Undoubtedly, rhizoremediation is considered as an ecofriendly and cost-effective alternative to physico-chemical methods for the remediation of TPH-contaminated soils. Despite many remarkable positive results under laboratory and greenhouse scale studies detailed above, the exploitation of rhizoremediation as a practically feasible technique under field conditions is still lacking, which generally makes this remedial option less attractive for the remediation industry or policy makers. As a biological process dependent on host plant species, contaminant characteristics, soil type, environmental conditions, and microbial activities, rhizoremediation is rarely recommended as a remediation technique, because of the inability to determine accurately the duration for complete remediation of TPH contaminants (Montpetit and Lachapelle 2015; 2016). Additionally, the successful application of 
the rhizoremediation strategy is often limited by the lack of scientifically proven, realtime methods to monitor the survival and activity of microorganisms involved (Dueholm et al. 2015). Many impacted sites in peri-urban areas need to be decontaminated over a short period, which can be incompatible with the application of rhizoremediation in situ. The above limitations are, therefore, the main obstacles in the decision-making process for using this remediation technique to manage TPH-contaminated soils at the field scale (Correa-García et al. 2018).

Nevertheless, the rhizoremediation strategy is particularly well-suited to field sites with low to moderate TPH levels (within plants' tolerance) and remote, vacant, or underutilized sites where conventional quick clean-up methods are economically infeasible or impossible and human health is not an immediate concern (Cundy et al. 2015). The use of plant-based systems in contaminated sites can be defined as risk-based management strategies, where soil functions and structures are preserved and protected while diminishing or eliminating the mass flux of the contaminants to receptors (Cundy et al. 2016). In addition, phyto-management approaches can provide other benefits, such as biomass generation, amenity and leisure and ecosystem services, preparation of suitable conditions prior to redevelopment, or other site regeneration strategies. Notably, in terms of costs involved, cultivating a suitable remediating plant on one acre of land can be accomplished at a cost ranging from 2 to 4 orders of magnitude less than other competing technologies such as soil excavation, pump-and-treat, and reburial (Kamath et al. 2004b; Rock and Sayre 1998). However, details about rhizoremediation cost for field application are not typically provided in recent academic publications. Also, commercial reports containing such information are not readily accessible due to confidentiality issues. Therefore, apart from knowledge 
of the limitations of the rhizoremediation technique and promising results from field trials, associated costs should be published to make the remedial approach more acceptable by the public and private sectors, and become a routine treatment option for TPH-impacted sites in the future.

\section{Future perspectives}

In spite of reports concerning the important role of plants in rhizoremediation of TPH-contaminated soils, strong evidence shows that it is the rhizosphere microorganisms that are main organisms involved in the rhizoremediation. Given that plants and their associated microorganisms co-evolved, the selection of suitable combinations of plants and microbes is of crucial importance. In this context, native plants that show their tolerance to petroleum hydrocarbons should be used in preference to exotic plants, because this would offer an economically feasible and environmentally sustainable option for the reclamation of TPH-polluted sites in any specific location. Although the decontamination process utilizing plants and their microbial associates in the rhizosphere is typically slow in nature, there are several techniques including biostimulation and bioaugmentation that are able to speed up the remediation process. These techniques can be combined in an integrated rhizoremediation system for maximizing remediation results. To broaden the scope of rhizoremediation and for more satisfactory efficiency of the process, future endeavours should include: (i) determining the potential of plant-derived biosurfactants for their ability to increase bioavailability for TPH degradation by microorganisms, (ii) studying the effect of inoculation of indigenous microbial consortia combining PGP, hydrocarbon-degrading, and surfactant-producing microorganisms, (iii) setting up large scale demonstration experiments using integrated rhizoremediation approaches, and (iv) applying genomics-based 
techniques for a better understanding the interactions between plants and their rhizosphere microbial communities. The latter approach could help us understand how complex organic compounds, such as TPH, are co-metabolically degraded in soil systems and, therefore, assist in setting up novel and highly efficient rhizoremediation systems.

\section{References}

Abbaspour A, Zohrabi F, Dorostkar V, Faz A, Acosta JA (2020) Remediation of an oilcontaminated soil by two native plants treated with biochar and mycorrhizae. $J$ Environ Manage 254: 109755.

Abdulsalam S, Bugaje I, Adefila S, Ibrahim S (2011) Comparison of biostimulation and bioaugmentation for remediation of soil contaminated with spent motor oil. EnvironSciTechnol 8: 187-194.

Adam G, Duncan H (2002) Influence of diesel fuel on seed germination. Environ Pollut 120: 363-370.

Adams GO, Fufeyin PT, Okoro SE, Ehinomen I (2015) Bioremediation, biostimulation and bioaugmention: a review. Int J Environ Bioremediat Biodegrad 3: 28-39.

Agamuthu P, Abioye O, Aziz AA (2010) Phytoremediation of soil contaminated with used lubricating oil using Jatropha curcas. J Hazard Mater 179: 891-894.

Agarry S, Aremu M, Aworanti O (2014) Biostimulation and phytoremediation treatment strategies of gasoline-nickel Co-contaminated soil. Soil Sediment Contam 23: 227244.

Agnello AC, Huguenot D, Van Hullebusch ED, Esposito G (2014) Enhanced phytoremediation: a review of low molecular weight organic acids and surfactants used as amendments. Crit Rev Environ Sci Technol 44: 2531-2576.

Alarcón A, Davies Jr FT, Autenrieth RL, Zuberer DA (2008) Arbuscular mycorrhiza and petroleum-degrading microorganisms enhance phytoremediation of petroleumcontaminated soil. Int J Phytoremediation 10: 251-263.

Allamin IA, Halmi MIE, Yasid NA, Ahmad SA, Abdullah SRS, Shukor Y (2020) Rhizodegradation of Petroleum Oily Sludge-contaminated Soil Using Cajanus cajan Increases the Diversity of Soil Microbial Community. Sci Rep 10: 1-11.

Allard-Massicotte R, Tessier L, Lécuyer F, Lakshmanan V, Lucier J-F, Garneau D, Caudwell L, Vlamakis H, Bais HP, Beauregard PB (2016) Bacillus subtilis early colonization of Arabidopsis thaliana roots involves multiple chemotaxis receptors. MBio 7: e01664-01616.

Almansoory AF, Hasan HA, Idris M, Abdullah SRS, Anuar N (2015) Potential application of a biosurfactant in phytoremediation technology for treatment of gasolinecontaminated soil. Ecol Eng 84: 113-120.

Alrumman SA, Standing DB, Paton GI (2015) Effects of hydrocarbon contamination on soil microbial community and enzyme activity. J King Saud Univ Sci 27: 31-41.

Andreolli M, Lampis S, Brignoli P, Vallini G (2015) Bioaugmentation and biostimulation as strategies for the bioremediation of a burned woodland soil contaminated by toxic hydrocarbons: a comparative study. J Environ Manage 153: 121-131.

Anyasi RO, Atagana $\mathrm{HI}$ (2018) Profiling of plants at petroleum contaminated site for phytoremediation. Int J Phytoremediation 20: 352-361. 
Anza M, Salazar O, Epelde L, Becerril JM, Alkorta I, Garbisu C (2019) Remediation of organically contaminated soil through the combination of assisted phytoremediation and bioaugmentation. Appl Sci 9: 4757.

Asemoloye MD, Ahmad R, Jonathan SG (2018) Transcriptomic responses of catalase, peroxidase and laccase encoding genes and enzymatic activities of oil spill inhabiting rhizospheric fungal strains. Environ Pollut 235: 55-64.

Asghar HN, Rafique HM, Khan MY, Zahir ZA (2017) Phytoremediation of light crude oil by maize (Zea mays L.) bio-augmented with plant growth promoting bacteria. Soil Sediment Contam 26: 749-763.

Ayotamuno JM, Kogbara RB, Agoro OS (2009) Biostimulation supplemented with phytoremediation in the reclamation of a petroleum contaminated soil. World $\mathrm{J}$ Microbiol Biotechnol 25: 1567-1572.

Azubuike CC, Chikere CB, Okpokwasili GC (2016) Bioremediation techniquesclassification based on site of application: principles, advantages, limitations and prospects. World J Microbiol Biotechnol 32: 180.

Bais HP, Weir TL, Perry LG, Gilroy S, Vivanco JM (2006) The role of root exudates in rhizosphere interactions with plants and other organisms. Annu Rev Plant Biol 57: 233-266.

Balasubramaniyam A (2015) The Influence of plants in the remediation of petroleum hydrocarbon-contaminated sites. Pharmaceutical Analytical Chemistry: Open Access 1: 1-11.

Baoune H, Aparicio JD, Acuña A, El Hadj-khelil AO, Sanchez L, Polti MA, Alvarez A (2019) Effectiveness of the Zea mays-Streptomyces association for the phytoremediation of petroleum hydrocarbons impacted soils. Ecotoxicol Environ Saf 184: 109591.

Barati M, Bakhtiari F, Mowla D, Safarzadeh S (2017) Total petroleum hydrocarbon degradation in contaminated soil as affected by plants growth and biochar. Environ Earth Sci 76: 688.

Barati M, Bakhtiari F, Mowla D, Safarzadeh S (2018) Comparison of the effects of poultry manure and its biochar on barley growth in petroleum-contaminated soils. Int $\mathrm{J}$ Phytoremediation 20: 98-103.

Bargiela R, Herbst FA, Martínez-Martínez M, Seifert J, Rojo D, Cappello S, Genovese M, Crisafi F, Denaro R, Chernikova TN (2015) Metaproteomics and metabolomics analyses of chronically petroleum-polluted sites reveal the importance of general anaerobic processes uncoupled with degradation. Proteomics 15: 3508-3520.

Basumatary B, Bordoloi S, Sarma HP (2012) Crude oil-contaminated soil phytoremediation by using Cyperus brevifolius (Rottb.) Hassk. Water, Air, Soil Pollut 223: 3373-3383.

Beal MA, Meier MJ, Williams A, Rowan-Carroll A, Gagné R, Lindsay SJ, Fitzgerald T, Hurles ME, Marchetti F, Yauk CL (2019) Paternal exposure to benzo (a) pyrene induces genome-wide mutations in mouse offspring. Commun Biol 2: 1-10.

Beckingham B, Ghosh U (2017) Differential bioavailability of polychlorinated biphenyls associated with environmental particles: Microplastic in comparison to wood, coal and biochar. Environ Pollut 220: 150-158.

Begum N, Qin C, Ahanger MA, Raza S, Khan MI, Ahmed N, Ashraf M, Zhang L (2019) Role of Arbuscular Mycorrhizal Fungi in Plant Growth Regulation: Implications in Abiotic Stress Tolerance. Front Plant Sci 10: 1068.

Bell TH, Hassan SE-D, Lauron-Moreau A, Al-Otaibi F, Hijri M, Yergeau E, St-Arnaud M (2014) Linkage between bacterial and fungal rhizosphere communities in hydrocarbon-contaminated soils is related to plant phylogeny. ISME J 8: 331-343.

Benson A, Ram G, John A, Melvin Joe M (2017) Inoculation of 1-aminocyclopropane-1carboxylate deaminase-producing bacteria along with biosurfactant application enhances the phytoremediation efficiency of Medicago sativa in hydrocarboncontaminated soils. Bioremediation J 21: 20-29.

Berg G, Smalla K (2009) Plant species and soil type cooperatively shape the structure and function of microbial communities in the rhizosphere. FEMS Microbiol Ecol 68: 113. 
Bertin C, Yang X, Weston LA (2003) The role of root exudates and allelochemicals in the rhizosphere. Plant Soil 256: 67-83.

Beškoski VP, Gojgić-Cvijović G, Milić J, llić M, Miletić S, Šolević T, Vrvić MM (2011) Ex situ bioremediation of a soil contaminated by mazut (heavy residual fuel oil)-A field experiment. Chemosphere 83: 34-40.

Betancur-Corredor B, Pino NJ, Cardona S, Peñuela GA (2015) Evaluation of biostimulation and Tween 80 addition for the bioremediation of long-term DDT-contaminated soil. J Environ Sci (China) 28: 101-109.

Bolan N, Kunhikrishnan A, Gibbs J (2013) Rhizoreduction of arsenate and chromate in Australian native grass, shrub and tree vegetation. Plant Soil 367: 615-625.

Bolan NS, Naidu R, Mahimairaja S, Baskaran S (1994) Influence of low-molecular-weight organic acids on the solubilization of phosphates. Biol Fertility Soils 18: 311-319.

Bolan NS, Park JH, Robinson B, Naidu R, Huh KY (2011) Phytostabilization: a green approach to contaminant containment. Adv Agron. Elsevier.

Boldt-Burisch K, Naeth MA, Schneider U, Schneider B, Hüttl RF (2018) Plant growth and arbuscular mycorrhizae development in oil sands processing by-products. Sci Total Environ 621: 30-39.

Boopathy R (2000) Factors limiting bioremediation technologies. Bioresour Technol 74: 6367.

Brink SC (2016) Unlocking the secrets of the rhizosphere. Trends Plant Sci 21: 169-170.

Bruederle A, Hodler R (2019) Effect of oil spills on infant mortality in Nigeria. Proc Natl Acad Sci USA 116: 5467-5471.

Cai B, Ma J, Yan G, Dai X, Li M, Guo S (2016) Comparison of phytoremediation, bioaugmentation and natural attenuation for remediating saline soil contaminated by heavy crude oil. Biochem Eng J 112: 170-177.

Calvo P, Nelson L, Kloepper JW (2014) Agricultural uses of plant biostimulants. Plant Soil 383: 3-41.

Cantrell KB, Hunt PG, Uchimiya M, Novak JM, Ro KS (2012) Impact of pyrolysis temperature and manure source on physicochemical characteristics of biochar. Bioresour Technol 107: 419-428.

Cartmill AD, Cartmill DL, Alarcón A (2014) Controlled release fertilizer increased phytoremediation of petroleum-contaminated sandy soil. Int J Phytoremediation 16: 285-301.

Chandra S, Sharma R, Singh K, Sharma A (2013) Application of bioremediation technology in the environment contaminated with petroleum hydrocarbon. Ann Microbiol 63: 417-431.

Chaudhry Q, Blom-Zandstra M, Gupta SK, Joner E (2005) Utilising the synergy between plants and rhizosphere microorganisms to enhance breakdown of organic pollutants in the environment (15 pp). Environ Sci Pollut Res 12: 34-48.

Chefetz B, Deshmukh AP, Hatcher PG, Guthrie EA (2000) Pyrene sorption by natural organic matter. Environ Sci Technol 34: 2925-2930.

Chen M, Xu P, Zeng G, Yang C, Huang D, Zhang J (2015) Bioremediation of soils contaminated with polycyclic aromatic hydrocarbons, petroleum, pesticides, chlorophenols and heavy metals by composting: applications, microbes and future research needs. Biotechnol Adv 33: 745-755.

Cheng K, Lai K, Wong J (2008) Effects of pig manure compost and nonionic-surfactant Tween 80 on phenanthrene and pyrene removal from soil vegetated with Agropyron elongatum. Chemosphere 73: 791-797.

Cheng L, Zhou Q, Yu B (2019) Responses and roles of roots, microbes, and degrading genes in rhizosphere during phytoremediation of petroleum hydrocarbons contaminated soil. Int J Phytoremediation 21: 1161-1169.

Chepelev NL, Moffat ID, Bowers WJ, Yauk CL (2015) Neurotoxicity may be an overlooked consequence of benzo [a] pyrene exposure that is relevant to human health risk assessment. Mutat Res Rev Mutat Res 764: 64-89. 
Chirakkara RA, Reddy KR (2015) Biomass and chemical amendments for enhanced phytoremediation of mixed contaminated soils. Ecol Eng 85: 265-274.

Chowdhury S, Farrell M, Bolan N (2014) Photoassimilated carbon allocation in a wheat plant-soil system as affected by soil fertility and land-use history. Plant Soil 383: 173-189.

Chowdhury S, Thangarajan R, Bolan N, O'Reilly-Wapstra J, Kunhikrishnan A, Naidu R (2017) Nitrification potential in the rhizosphere of Australian native vegetation. Soil Res 55: 58-69.

Chuluun B, Shah SH, Rhee J-S (2014) Bioaugmented phytoremediation: A strategy for reclamation of diesel oil-contaminated soils. Int J Agric Biol 16: 624-628.

Chung N, Alexander M (1999) Effect of concentration on sequestration and bioavailability of two polycyclic aromatic hydrocarbons. Environ Sci Technol 33: 3605-3608.

Cook RL, Hesterberg D (2013) Comparison of trees and grasses for rhizoremediation of petroleum hydrocarbons. Int J Phytoremediation 15: 844-860.

Correa-García S, Pande P, Séguin A, St-Arnaud M, Yergeau E (2018) Rhizoremediation of petroleum hydrocarbons: a model system for plant microbiome manipulation. Microb Biotechnol 11: 819-832.

Cundy A, Bardos P, Puschenreiter M, Witters N, Mench M, Bert V, Friesl-Hanl W, Müller I, Weyens N, Vangronsveld J (2015) Developing effective decision support for the application of "gentle" remediation options: The GREENLAND project. Remediation 25: 101-114.

Cundy A, Bardos R, Puschenreiter M, Mench M, Bert V, Friesl-Hanl W, Müller I, Li X, Weyens N, Witters N (2016) Brownfields to green fields: realising wider benefits from practical contaminant phytomanagement strategies. J Environ Manage 184: 67-77.

Cunningham SD, Berti WR, Huang JW (1995) Phytoremediation of contaminated soils. Trends Biotechnol 13: 393-397.

Cuypers C, Clemens R, Grotenhuis T, Rulkens W (2001) Prediction of petroleum hydrocarbon bioavailability in contaminated soils and sediments. Soil and Sediment Contamination 10: 459-482.

Cuypers C, Pancras T, Grotenhuis T, Rulkens W (2002) The estimation of PAH bioavailability in contaminated sediments using hydroxypropyl- $\beta$-cyclodextrin and Triton X-100 extraction techniques. Chemosphere 46: 1235-1245.

Dagher D, de la Providencia I, Pitre F, St-Arnaud M, Hijri M (2019) Plant identity shaped rhizospheric microbial communities more strongly than bacterial bioaugmentation in petroleum hydrocarbon-polluted sediments. Front Microbiol 10: 2144.

De Tender C, Haegeman A, Vandecasteele B, Clement L, Cremelie P, Dawyndt P, Maes $M$, Debode J (2016) Dynamics in the strawberry rhizosphere microbiome in response to biochar and Botrytis cinerea leaf infection. Front Microbiol 7: 2062.

Dealtry S, Ghizelini AM, Mendonça-Hagler L, Chaloub RM, Reinert F, de Campos TM, Gomes N, Smalla K (2018) Petroleum contamination and bioaugmentation in bacterial rhizosphere communities from Avicennia schaueriana. Braz J Microbiol 49: 757-769.

Dhote M, Kumar A, Jajoo A, Juwarkar A (2017) Assessment of hydrocarbon degradation potentials in a plant-microbe interaction system with oil sludge contamination: A sustainable solution. Int J Phytoremediation 19: 1085-1092.

Dietz S, Herz K, Döll S, Haider S, Jandt U, Bruelheide H, Scheel D (2019) Semi-polar root exudates in natural grassland communities. Ecol Evol 9: 5526-5541.

Dong R, Gu L, Guo C, Xun F, Liu J (2014) Effect of PGPR Serratia marcescens BC-3 and AMF Glomus intraradices on phytoremediation of petroleum contaminated soil. Ecotoxicology 23: 674-680.

dos Santos JJ, Maranho LT (2018) Rhizospheric microorganisms as a solution for the recovery of soils contaminated by petroleum: A review. J Environ Manage 210: 104113. 
Drever J, Stillings $L$ (1997) The role of organic acids in mineral weathering. Colloids Surf Physicochem Eng Aspects 120: 167-181.

Driai S, Verdin A, Laruelle F, Beddiar A, Sahraoui AL-H (2015) Is the arbuscular mycorrhizal fungus Rhizophagus irregularis able to fulfil its life cycle in the presence of diesel pollution? Int Biodeterior Biodegrad 105: 58-65.

Dubrovskaya E, Pozdnyakova N, Golubev S, Muratova A, Grinev V, Bondarenkova A, Turkovskaya $O$ (2017) Peroxidases from root exudates of Medicago sativa and Sorghum bicolor: Catalytic properties and involvement in $\mathrm{PAH}$ degradation. Chemosphere 169: 224-232.

Dueholm MS, Marques IG, Karst SM, D'Imperio S, Tale VP, Lewis D, Nielsen PH, Nielsen $\mathrm{JL}$ (2015) Survival and activity of individual bioaugmentation strains. Bioresour Technol 186: 192-199.

Ebadi A, Sima NAK, Olamaee M, Hashemi M, Nasrabadi RG (2018) Remediation of saline soils contaminated with crude oil using the halophyte Salicornia persica in conjunction with hydrocarbon-degrading bacteria. J Environ Manage 219: 260-268.

el Zahar Haichar F, Marol C, Berge O, Rangel-Castro JI, Prosser JI, Balesdent Jm, Heulin T, Achouak W (2008) Plant host habitat and root exudates shape soil bacterial community structure. ISME J 2: 1221.

Ely CS, Smets BF (2017) Bacteria from wheat and cucurbit plant roots metabolize PAHs and aromatic root exudates: implications for rhizodegradation. Int $\mathrm{J}$ Phytoremediation 19: 877-883.

Escalante-Espinosa E, Gallegos-Martínez M, Favela-Torres E, Gutiérrez-Rojas M (2005) Improvement of the hydrocarbon phytoremediation rate by Cyperus laxus Lam. inoculated with a microbial consortium in a model system. Chemosphere 59: 405413.

Esperschütz J, Buegger F, Winkler J, Munch J, Schloter M, Gattinger A (2009) Microbial response to exudates in the rhizosphere of young beech trees (Fagus sylvatica L.) after dormancy. Soil Biol Biochem 41: 1976-1985.

Faizal A, Geelen D (2013) Saponins and their role in biological processes in plants. Phytochem Rev 12: 877-893.

Falkova M, Vakh C, Shishov A, Zubakina E, Moskvin A, Moskvin L, Bulatov A (2016) Automated IR determination of petroleum products in water based on sequential injection analysis. Talanta 148: 661-665.

Fan K, Cardona C, Li Y, Shi Y, Xiang X, Shen C, Wang H, Gilbert JA, Chu H (2017) Rhizosphere-associated bacterial network structure and spatial distribution differ significantly from bulk soil in wheat crop fields. Soil Biol Biochem 113: 275-284.

Fatima K, Afzal M, Imran A, Khan QM (2015) Bacterial rhizosphere and endosphere populations associated with grasses and trees to be used for phytoremediation of crude oil contaminated soil. Bull Environ Contam Toxicol 94: 314-320.

Fenibo EO, ljoma GN, Selvarajan R, Chikere CB (2019) Microbial Surfactants: The Next Generation Multifunctional Biomolecules for Applications in the Petroleum Industry and Its Associated Environmental Remediation. Microorganisms 7: 581.

Fletcher JS, Hegde RS (1995) Release of phenols by perennial plant roots and their potential importance in bioremediation. Chemosphere 31: 3009-3016.

Franchi E, Agazzi G, Rolli E, Borin S, Marasco R, Chiaberge S, Conte A, Filtri P, Pedron F, Rosellini I (2016) Exploiting Hydrocarbon-Degrading Indigenous Bacteria for Bioremediation and Phytoremediation of a Multicontaminated Soil. Chem Eng Technol 39: 1676-1684.

Gagné-Bourque F, Bertrand A, Claessens A, Aliferis KA, Jabaji S (2016) Alleviation of drought stress and metabolic changes in timothy (Phleum pratense L.) colonized with Bacillus subtilis B26. Front Plant Sci 7: 584.

Gao Y, Ren L, Ling W, Gong S, Sun B, Zhang Y (2010a) Desorption of phenanthrene and pyrene in soils by root exudates. Bioresour Technol 101: 1159-1165. 
Gao Y, Ren L, Ling W, Kang F, Zhu X, Sun B (2010b) Effects of low-molecular-weight organic acids on sorption-desorption of phenanthrene in soils. Soil Sci Soc Am J 74: 51-59.

Gao Y, Wu S, Yu X, Wong MH (2010c) Dissipation gradients of phenanthrene and pyrene in the Rice rhizosphere. Environ Pollut 158: 2596-2603.

Gao Y, Yang Y, Ling W, Kong H, Zhu X (2011) Gradient distribution of root exudates and polycyclic aromatic hydrocarbons in rhizosphere soil. Soil Sci Soc Am J 75: 16941703.

Gao Y, Yuan X, Lin X, Sun B, Zhao Z (2015) Low-molecular-weight organic acids enhance the release of bound PAH residues in soils. Soil Tillage Res 145: 103-110.

Garcés-Ruiz M, Senés-Guerrero C, Declerck S, Cranenbrouck S (2019) Community composition of arbuscular mycorrhizal fungi associated with native plants growing in a petroleum-polluted soil of the Amazon region of Ecuador. MicrobiologyOpen 8: e00703.

Garcés Mejía AC, Pino NJ, Penuela GA (2018) Effect of Secondary Metabolites Present in Brassica nigra Root Exudates on Anthracene and Phenanthrene Degradation by Rhizosphere Microorganism. Environ Eng Sci 35: 203-209.

Garrido-Sanz D, Redondo-Nieto M, Guirado M, Pindado Jiménez O, Millán R, Martin M, Rivilla R (2019) Metagenomic Insights into the Bacterial Functions of a DieselDegrading Consortium for the Rhizoremediation of Diesel-Polluted Soil. Genes 10: 456.

Gaskin S, Bentham R (2005) Comparison of enrichment methods for the isolation of pyrenedegrading bacteria. Int Biodeterior Biodegrad 56: 80-85.

Gaskin SE, Bentham RH (2010) Rhizoremediation of hydrocarbon contaminated soil using Australian native grasses. Sci Total Environ 408: 3683-3688.

Gerhardt KE, Huang X-D, Glick BR, Greenberg BM (2009) Phytoremediation and rhizoremediation of organic soil contaminants: potential and challenges. Plant Sci 176: 20-30.

Ghalamboran M, Kordkheli S, Bernard F (2020) Enzymatic response and metal ion content in roots of corn and broad beans planted in soil contaminated with gasoline. Int $\mathrm{J}$ Environ Sci Technol 17: 973-982.

Gkorezis P, Daghio M, Franzetti A, Van Hamme JD, Sillen W, Vangronsveld J (2016) The interaction between plants and bacteria in the remediation of petroleum hydrocarbons: an environmental perspective. Front Microbiol 7: 1836.

Glick BR (2010) Using soil bacteria to facilitate phytoremediation. Biotechnol Adv 28: 367374.

Graj W, Lisiecki P, Szulc A, Chrzanowski Ł, Wojtera-Kwiczor J (2013) Bioaugmentation with petroleum-degrading consortia has a selective growth-promoting impact on crop plants germinated in diesel oil-contaminated soil. Water, Air, Soil Pollut 224: 1676.

Grayston S, Vaughan D, Jones D (1997) Rhizosphere carbon flow in trees, in comparison with annual plants: the importance of root exudation and its impact on microbial activity and nutrient availability. Appl Soil Ecol 5: 29-56.

Gurska J, Wang W, Gerhardt KE, Khalid AM, Isherwood DM, Huang X-D, Glick BR, Greenberg BM (2009) Three year field test of a plant growth promoting rhizobacteria enhanced phytoremediation system at a land farm for treatment of hydrocarbon waste. Environ Sci Technol 43: 4472-4479.

Han T, Zhao Z, Bartlam M, Wang Y (2016) Combination of biochar amendment and phytoremediation for hydrocarbon removal in petroleum-contaminated soil. Environ Sci Pollut Res 23: 21219-21228.

Hawthorne SB, Grabanski CB, Martin E, Miller DJ (2000) Comparisons of Soxhlet extraction, pressurized liquid extraction, supercritical fluid extraction and subcritical water extraction for environmental solids: recovery, selectivity and effects on sample matrix. J Chromatogr 892: 421-433. 
Hernández-Ortega HA, Alarcón A, Ferrera-Cerrato R, Zavaleta-Mancera HA, LópezDelgado HA, Mendoza-López MR (2012) Arbuscular mycorrhizal fungi on growth, nutrient status, and total antioxidant activity of Melilotus albus during phytoremediation of a diesel-contaminated substrate. J Environ Manage 95: S319S324.

Herz K, Dietz S, Gorzolka K, Haider S, Jandt U, Scheel D, Bruelheide H (2018) Linking root exudates to functional plant traits. PLoS One 13.

Hong SH, Ryu H, Kim J, Cho K-S (2011) Rhizoremediation of diesel-contaminated soil using the plant growth-promoting rhizobacterium Gordonia sp. S2RP-17. Biodegradation 22: 593-601.

Hou J, Liu W, Wang B, Wang Q, Luo Y, Franks AE (2015) PGPR enhanced phytoremediation of petroleum contaminated soil and rhizosphere microbial community response. Chemosphere 138: 592-598.

Huang X-D, El-Alawi Y, Gurska J, Glick BR, Greenberg BM (2005) A multi-process phytoremediation system for decontamination of persistent total petroleum hydrocarbons (TPHs) from soils. Microchem J 81: 139-147.

Huang X-F, Chaparro JM, Reardon KF, Zhang R, Shen Q, Vivanco JM (2014) Rhizosphere interactions: root exudates, microbes, and microbial communities. Botany 92: 267275.

Hunt LJ, Duca D, Dan T, Knopper LD (2018) Petroleum hydrocarbon (PHC) uptake in plants: A literature review. Environ Pollut.

Hussain F, Hussain I, Khan AHA, Muhammad YS, Iqbal M, Soja G, Reichenauer TG, Yousaf S (2018a) Combined application of biochar, compost, and bacterial consortia with Italian ryegrass enhanced phytoremediation of petroleum hydrocarbon contaminated soil. Environ Exp Bot 153: 80-88.

Hussain I, Aleti G, Naidu R, Puschenreiter M, Mahmood Q, Rahman MM, Wang F, Shaheen S, Syed JH, Reichenauer TG (2018b) Microbe and plant assisted-remediation of organic xenobiotics and its enhancement by genetically modified organisms and recombinant technology: a review. Sci Total Environ 628: 1582-1599.

Hussain I, Puschenreiter M, Gerhard S, Sani SGAS, Reichenauer TG (2019) Differentiation between physical and chemical effects of oil presence in freshly spiked soil during rhizoremediation trial. Environ Sci Pollut Res 26: 18451-18464.

Hussain I, Puschenreiter M, Gerhard S, Schöftner P, Yousaf S, Wang A, Syed JH, Reichenauer TG (2018c) Rhizoremediation of petroleum hydrocarboncontaminated soils: improvement opportunities and field applications. Environ Exp Bot 147: 202-219.

Hutchinson S, Schwab A, Banks M (2003) Biodegradation of petroleum hydrocarbons in the rhizosphere. Phytoremediation: transformation and control of contaminants: 355-386.

Hutchinson SL, Banks M, Schwab A (2001) Phytoremediation of aged petroleum sludge. J Environ Qual 30: 395-403.

Iffis B, St-Arnaud M, Hijri M (2017) Petroleum contamination and plant identity influence soil and root microbial communities while AMF spores retrieved from the same plants possess markedly different communities. Front Plant Sci 8: 1381.

Iffis B, St-Arnaud M, Hijri M (2016) Petroleum hydrocarbon contamination, plant identity and arbuscular mycorrhizal fungal (AMF) community determine assemblages of the AMF spore-associated microbes. Environ Microbiol 18: 2689-2704.

Imron MF, Kurniawan SB, Ismail NI, Abdullah SRS (2019) Future challenges in diesel biodegradation by bacteria isolates: A review. J Clean Prod: 119716.

Ingrid L, Sahraoui AL-H, Frédéric L, Yolande D, Joël F (2016) Arbuscular mycorrhizal wheat inoculation promotes alkane and polycyclic aromatic hydrocarbon biodegradation: Microcosm experiment on aged-contaminated soil. Environ Pollut 213: 549-560.

Jia H, Lu H, Liu J, Li J, Dai M, Yan C (2016) Effects of root exudates on the leachability, distribution, and bioavailability of phenanthrene and pyrene from mangrove sediments. Environ Sci Pollut Res 23: 5566-5576. 
Jussila MM, Zhao J, Suominen L, Lindström K (2007) TOL plasmid transfer during bacterial conjugation in vitro and rhizoremediation of oil compounds in vivo. Environ Pollut 146: 510-524.

Kai M, Effmert U, Piechulla B (2016) Bacterial-plant-interactions: approaches to unravel the biological function of bacterial volatiles in the rhizosphere. Front Microbiol 7: 108.

Kamath R, Rentz J, Schnoor JL, Alvarez P (2004a) Phytoremediation of hydrocarboncontaminated soils: principles and applications. Stud Surf Sci Catal 151: 447-478.

Kamath R, Rentz J, Schnoor JL, Alvarez P (2004b) Phytoremediation of hydrocarboncontaminated soils: principles and applications. Stud Surf Sci Catal. Elsevier.

Kawasaki A, Warren CR, Kertesz MA (2016) Specific influence of white clover on the rhizosphere microbial community in response to polycyclic aromatic hydrocarbon (PAH) contamination. Plant Soil 401: 365-379.

Khan MAI, Biswas B, Smith E, Naidu R, Megharaj M (2018) Toxicity assessment of fresh and weathered petroleum hydrocarbons in contaminated soil-a review. Chemosphere 212: 755-767.

Khan S, Afzal M, lqbal S, Khan QM (2013) Plant-bacteria partnerships for the remediation of hydrocarbon contaminated soils. Chemosphere 90: 1317-1332.

Kiamarsi Z, Kafi M, Soleimani M, Nezami A, Lutts S (2020) Conjunction of Vetiveria zizanioides $\mathrm{L}$. and oil-degrading bacteria as a promising technique for remediation of crude oil-contaminated soils. J Clean Prod 253: 119719.

Kirkpatrick WD, White Jr P, Wolf D, Thoma G, Reynolds C (2006) Selecting plants and nitrogen rates to vegetate crude-oil-contaminated soil. Int $\mathrm{J}$ Phytoremediation 8: 285-297.

Kobayashi T, Kaminaga H, Navarro RR, limura Y (2012) Application of aqueous saponin on the remediation of polycyclic aromatic hydrocarbons-contaminated soil. Journal of Environmental Science and Health, Part A 47: 1138-1145.

Kogbara RB, Ogar I, Okparanma RN, Ayotamuno JM (2016) Treatment of petroleum drill cuttings using bioaugmentation and biostimulation supplemented with phytoremediation. Journal of Environmental Science and Health, Part A 51: 714721.

Kotoky R, Pandey P (2019) Rhizosphere mediated biodegradation of benzo (A) pyrene by surfactin producing soil bacilli applied through Melia azadirachta rhizosphere. Int $\mathrm{J}$ Phytoremediation: 1-10.

Kowalchuk GA, Buma DS, de Boer W, Klinkhamer PG, van Veen JA (2002) Effects of above-ground plant species composition and diversity on the diversity of soil-borne microorganisms. Antonie Van Leeuwenhoek 81: 509.

Krishnamurti G, Cieslinski G, Huang P, Van Rees K (1997) Kinetics of cadmium release from soils as influenced by organic acids: implication in cadmium availability. $J$ Environ Qual 26: 271-277.

Kritikos M (2018) Developing a Regulatory Framework on GMO Releases. EU PolicyMaking on GMOs. Springer.

Kuiper I, Lagendijk EL, Bloemberg GV, Lugtenberg BJ (2004) Rhizoremediation: a beneficial plant-microbe interaction. Mol Plant-Microbe Interact 17: 6-15.

Kuo H-C, Juang D-F, Yang L, Kuo W-C, Wu Y-M (2014) Phytoremediation of soil contaminated by heavy oil with plants colonized by mycorrhizal fungi. Int $\mathrm{J}$ Environ Sci Technol 11: 1661-1668.

Kuppusamy S, Maddela NR, Megharaj M, Venkateswarlu K (2020) An Overview of Total Petroleum Hydrocarbons. Total Petroleum Hydrocarbons. Springer.

Kuyukina MS, Ivshina IB, Makarov SO, Litvinenko LV, Cunningham CJ, Philp JC (2005) Effect of biosurfactants on crude oil desorption and mobilization in a soil system. Environ Int 31: 155-161.

Kuzyakov Y, Xu X (2013) Competition between roots and microorganisms for nitrogen: mechanisms and ecological relevance. New Phytol 198: 656-669. 
Lacalle RG, Gómez-Sagasti MT, Artetxe U, Garbisu C, Becerril JM (2018) Brassica napus has a key role in the recovery of the health of soils contaminated with metals and diesel by rhizoremediation. Sci Total Environ 618: 347-356.

Leahy JG, Colwell RR (1990) Microbial degradation of hydrocarbons in the environment. Microbiol Mol Biol Rev 54: 305-315.

LeFevre GH, Hozalski RM, Novak PJ (2013) Root exudate enhanced contaminant desorption: an abiotic contribution to the rhizosphere effect. Environ Sci Technol 47: 11545-11553.

Lenoir I, Fontaine J, Sahraoui AL-H (2016) Arbuscular mycorrhizal fungal responses to abiotic stresses: a review. Phytochemistry 123: 4-15.

Liao C, Xu W, Lu G, Deng F, Liang X, Guo C, Dang Z (2016) Biosurfactant-enhanced phytoremediation of soils contaminated by crude oil using maize (Zea mays. L). Ecol Eng 92: 10-17.

Lin Q, Mendelssohn IA (1998) The combined effects of phytoremediation and biostimulation in enhancing habitat restoration and oil degradation of petroleum contaminated wetlands. Ecol Eng 10: 263-274.

Lin Q, Mendelssohn IA, Graham SA, Hou A, Fleeger JW, Deis DR (2016) Response of salt marshes to oiling from the Deepwater Horizon spill: Implications for plant growth, soil surface-erosion, and shoreline stability. Sci Total Environ 557: 369-377.

Ling W, Sun R, Gao X, Xu R, Li H (2015) Low-molecular-weight organic acids enhance desorption of polycyclic aromatic hydrocarbons from soil. Eur J Soil Sci 66: 339347.

Lioussanne L, Jolicoeur M, St-Arnaud M (2008) Mycorrhizal colonization with Glomus intraradices and development stage of transformed tomato roots significantly modify the chemotactic response of zoospores of the pathogen Phytophthora nicotianae. Soil Biol Biochem 40: 2217-2224.

Liu C, Li C, Zheng F, Zhang H, Yu H (2019) Composition Identification and Allelopathic Effect of Root Exudates of Ginseng in Different Continuous Cropping Years. Acta Microsc 28.

Liu S, Lu Y, Yang C, Liu C, Ma L, Dang Z (2017a) Effects of modified biochar on rhizosphere microecology of rice (Oryza sativa L.) grown in As-contaminated soil. Environ Sci Pollut Res 24: 23815-23824.

Liu W, Sun J, Ding L, Luo Y, Chen M, Tang C (2013) Rhizobacteria (Pseudomonas sp. SB) assist phytoremediation of oily-sludge-contaminated soil by tall fescue (Testuca arundinacea L.). Plant Soil 371: 533-542.

Liu Z, Li Z, Zhong H, Zeng G, Liang Y, Chen M, Wu Z, Zhou Y, Yu M, Shao B (2017b) Recent advances in the environmental applications of biosurfactant saponins: a review. J Environ Chem Eng 5: 6030-6038.

Lozsan A, Rivas I, Rodriguez G, Martinez S, Pérez MÁ (2017) Determination of SurfaceActive Characteristics of a Natural Surfactant Extracted from Sapindus Saponaria. Tenside, Surfactants, Deterg 54: 109-117.

Lugtenberg BJ, Bloemberg GV (2004) Life in the rhizosphere. Pseudomonas. Springer.

Lundberg DS, Lebeis SL, Paredes SH, Yourstone S, Gehring J, Malfatti S, Tremblay J, Engelbrektson A, Kunin V, Del Rio TG (2012) Defining the core Arabidopsis thaliana root microbiome. Nature 488: 86-90.

Luo Q, Liang S, Huang Q (2018) Laccase induced degradation of perfluorooctanoic acid in a soil slurry. J Hazard Mater 359: 241-247.

Luo W, Zhu X, Chen W, Duan Z, Wang L, Zhou Y (2014) Mechanisms and strategies of microbial cometabolism in the degradation of organic compounds-chlorinated ethylenes as the model. Water Sci Technol 69: 1971-1983.

Macaulay BM, Rees D (2014) Bioremediation of oil spills: a review of challenges for research advancement. Ann Environ Sci 8: 9-37.

Mao X, Jiang R, Xiao W, Yu J (2015) Use of surfactants for the remediation of contaminated soils: a review. J Hazard Mater 285: 419-435. 
Maqbool F, Wang Z, Xu Y, Zhao J, Gao D, Zhao Y-G, Bhatti ZA, Xing B (2012) Rhizodegradation of petroleum hydrocarbons by Sesbania cannabina in bioaugmented soil with free and immobilized consortium. J Hazard Mater 237: 262269.

Marchand C, Jani Y, Kaczala F, Hijri M, Hogland W (2018) Physicochemical and Ecotoxicological Characterization of Petroleum Hydrocarbons and Trace Elements Contaminated Soil. Polycyc Aromatic Compounds: 1-12.

Martin BC, George SJ, Price CA, Ryan MH, Tibbett M (2014) The role of root exuded low molecular weight organic anions in facilitating petroleum hydrocarbon degradation: current knowledge and future directions. Sci Total Environ 472: 642-653.

Mena E, Villaseñor J, Rodrigo MA, Cañizares P (2016) Electrokinetic remediation of soil polluted with insoluble organics using biological permeable reactive barriers: effect of periodic polarity reversal and voltage gradient. Chem Eng J 299: 30-36.

Merkl N, Schultze-Kraft R, Arias M (2005a) Influence of fertilizer levels on phytoremediation of crude oil-contaminated soils with the tropical pasture grass Brachiaria brizantha (Hochst. ex a. rich.) stapf. Int J Phytoremediation 7: 217-230.

Merkl N, Schultze-Kraft R, Infante C (2005b) Assessment of tropical grasses and legumes for phytoremediation of petroleum-contaminated soils. Water Air Soil Pollut 165: 195-209.

Meudec A, Dussauze J, Deslandes E, Poupart N (2006) Evidence for bioaccumulation of PAHs within internal shoot tissues by a halophytic plant artificially exposed to petroleum-polluted sediments. Chemosphere 65: 474-481.

Miettinen H, Bomberg M, Nyyssönen M, Reunamo A, Jørgensen KS, Vikman M (2019) Oil degradation potential of microbial communities in water and sediment of Baltic Sea coastal area. PLoS One 14.

Mikolasch A, Donath M, Reinhard A, Herzer C, Zayadan B, Urich T, Schauer F (2019) Diversity and degradative capabilities of bacteria and fungi isolated from oilcontaminated and hydrocarbon-polluted soils in Kazakhstan. Appl Microbiol Biotechnol 103: 7261-7274.

Möbius D, Miller R, Fainerman VB (2001) Surfactants: chemistry, interfacial properties, applications. Elsevier.

Montpetit É, Lachapelle E (2015) Can policy actors learn from academic scientists? Env Polit 24: 661-680.

Montpetit É, Lachapelle E (2016) Information, values and expert decision-making: the case of soil decontamination. Policy Sci 49: 155-171.

Muffler K, Leipold D, Scheller M-C, Haas C, Steingroewer J, Bley T, Neuhaus HE, Mirata MA, Schrader J, Ulber R (2011) Biotransformation of triterpenes. Process Biochem 46: 1-15.

Muratova A, Dubrovskaya E, Golubev S, Grinev V, Chernyshova M, Turkovskaya O (2015) The coupling of the plant and microbial catabolisms of phenanthrene in the rhizosphere of Medicago sativa. J Plant Physiol 188: 1-8.

Muratova A, Pozdnyakova N, Golubev S, Wittenmayer L, Makarov O, Merbach W, Turkovskaya $O$ (2009) Oxidoreductase activity of sorghum root exudates in a phenanthrene-contaminated environment. Chemosphere 74: 1031-1036.

Musilova L, Ridl J, Polivkova M, Macek T, Uhlik O (2016) Effects of secondary plant metabolites on microbial populations: changes in community structure and metabolic activity in contaminated environments. Int J Mol Sci 17: 1205.

Nanekar S, Dhote M, Kashyap S, Singh S, Juwarkar AA (2015) Microbe assisted phytoremediation of oil sludge and role of amendments: a mesocosm study. Int J Environ Sci Technol 12: 193-202.

Nardeli SM, Saad CF, de Barros Rossetto P, Caetano VS, Ribeiro-Alves M, Paes JES, Danielowski R, da Maia LC, de Oliveira AC, Peixoto RS (2016) Transcriptional responses of Arabidopsis thaliana to oil contamination. Environ Exp Bot 127: 63-72.

Nedunuri K, Lowell C, Meade W, Vonderheide A, Shann J (2009) Management practices and phytoremediation by native grasses. Int J Phytoremediation 12: 200-214. 
NEPC NEPC (1999) National environment protection measure for the assessment of site contamination: impact statement.

Newman LA, Reynolds CM (2004) Phytodegradation of organic compounds. Curr Opin Biotechnol 15: 225-230.

Newman MM, Lorenz N, Hoilett N, Lee NR, Dick RP, Liles MR, Ramsier C, Kloepper JW (2016) Changes in rhizosphere bacterial gene expression following glyphosate treatment. Sci Total Environ 553: 32-41.

Nie M, Yang Q, Jiang L-F, Fang C-M, Chen J-K, Li B (2010) Do plants modulate biomass allocation in response to petroleum pollution? Biol Lett 6: 811-814.

Ofek-Lalzar M, Sela N, Goldman-Voronov M, Green SJ, Hadar Y, Minz D (2014) Niche and host-associated functional signatures of the root surface microbiome. Nat Commun 5: 4950.

Ollivier B, Magot M (2005) Petroleum microbiology. ASM Press Washington, DC.

Pacwa-Płociniczak M, Czapla J, Płociniczak T, Piotrowska-Seget Z (2019) The effect of bioaugmentation of petroleum-contaminated soil with Rhodococcus erythropolis strains on removal of petroleum from soil. Ecotoxicol Environ Saf 169: 615-622.

Paliwal V, Puranik S, Purohit HJ (2012) Integrated perspective for effective bioremediation. Appl Biochem Biotechnol 166: 903-924.

Panagos P, Van Liedekerke M, Yigini Y, Montanarella L (2013) Contaminated sites in Europe: review of the current situation based on data collected through a European network. J Environ Public Health 2013.

Park JH, Lamb D, Paneerselvam P, Choppala G, Bolan N, Chung J-W (2011) Role of organic amendments on enhanced bioremediation of heavy metal (loid) contaminated soils. J Hazard Mater 185: 549-574.

Patowary R, Patowary K, Devi A, Kalita MC, Deka S (2017) Uptake of total petroleum hydrocarbon (TPH) and polycyclic aromatic hydrocarbons (PAHs) by Oryza sativa L. grown in soil contaminated with crude oil. Bull Environ Contam Toxicol 98: 120126.

Pérez-Hernández I, Ochoa-Gaona $S$, Adams R, Rivera-Cruz M, Pérez-Hernández V, Jarquín-Sánchez A, Geissen V, Martínez-Zurimendi P (2017) Growth of four tropical tree species in petroleum-contaminated soil and effects of crude oil contamination. Environ Sci Pollut Res 24: 1769-1783.

Pilon-Smits E (2005) Phytoremediation. Annu Rev Plant Biol 56: 15-39.

Pinedo J, Ibáñez R, Lijzen J, Irabien A (2013) Assessment of soil pollution based on total petroleum hydrocarbons and individual oil substances. J Environ Manage 130: 7279.

Pizarro-Tobías P, Niqui JL, Roca A, Solano J, Fernández M, Bastida F, García C, Ramos $\mathrm{JL}$ (2015) Field trial on removal of petroleum-hydrocarbon pollutants using a microbial consortium for bioremediation and rhizoremediation. Environ Microbiol Rep 7: 85-94.

Płociniczak T, Fic E, Pacwa-Płociniczak M, Pawlik M, Piotrowska-Seget Z (2017) Improvement of phytoremediation of an aged petroleum hydrocarbon-contaminated soil by Rhodococcus erythropolis CD 106 strain. Int J Phytoremediation 19: 614620.

Qin G, Gong D, Fan M-Y (2013) Bioremediation of petroleum-contaminated soil by biostimulation amended with biochar. Int Biodeterior Biodegrad 85: 150-155.

Qixing Z, Zhang C, Zhineng Z, Weitao L (2011) Ecological remediation of hydrocarbon contaminated soils with weed plant. J Res Ecol 2: 97-106.

Ram G, Melvin Joe M, Devraj S, Benson A (2019) Rhamnolipid production using Shewanella seohaensis BS18 and evaluation of its efficiency along with phytoremediation and bioaugmentation for bioremediation of hydrocarbon contaminated soils. Int J Phytoremediation 21: 1375-1383.

Razavi BS, Zarebanadkouki M, Blagodatskaya E, Kuzyakov Y (2016) Rhizosphere shape of lentil and maize: spatial distribution of enzyme activities. Soil Biol Biochem 96: 229-237. 
Redfield AC (1958) The biological control of chemical factors in the environment. Am Sci 46: 230A-221.

Reid BJ, Jones KC, Semple KT (2000) Bioavailability of persistent organic pollutants in soils and sediments-a perspective on mechanisms, consequences and assessment. Environ Pollut 108: 103-112.

Rein A, Adam IK, Miltner A, Brumme K, Kästner M, Trapp S (2016) Impact of bacterial activity on turnover of insoluble hydrophobic substrates (phenanthrene and pyrene)-Model simulations for prediction of bioremediation success. J Hazard Mater 306: 105-114.

Rentz JA, Alvarez PJ, Schnoor JL (2005) Benzo [a] pyrene co-metabolism in the presence of plant root extracts and exudates: implications for phytoremediation. Environ Pollut 136: 477-484.

Rentz JA, Chapman B, Alvarez PJ, Schnoor JL (2003) Stimulation of hybrid poplar growth in petroleum-contaminated soils through oxygen addition and soil nutrient amendments. Int J Phytoremediation 5: 57-72.

Rezvani Borujeni S, Khavazi K, Asgharzadeh A, Rezvani Borujeni I (2018) Use of bacterial acc deaminase to increase oil (especially poly aromatic hydrocarbons) phytoremediation efficiency for maize (zea mays) seedlings. Int J Phytoremediation 20: 476-482.

Robichaud K, Stewart K, Labrecque M, Hijri M, Cherewyk J, Amyot M (2019) An ecological microsystem to treat waste oil contaminated soil: Using phytoremediation assisted by fungi and local compost, on a mixed-contaminant site, in a cold climate. Sci Total Environ 672: 732-742.

Rock SA, Sayre PG (1998) Phytoremediation of hazardous wastes: Potential regulatory acceptability. Remediation 8: 5-17.

Rodriguez-Campos J, Perales-Garcia A, Hernandez-Carballo J, Martinez-Rabelo F, Hernández-Castellanos B, Barois I, Contreras-Ramos SM (2019) Bioremediation of soil contaminated by hydrocarbons with the combination of three technologies: bioaugmentation, phytoremediation, and vermiremediation. J Soils Sed 19: 19811994.

Rohrbacher F, St-Arnaud M (2016) Root exudation: the ecological driver of hydrocarbon rhizoremediation. Agronomy 6: 19.

Rojo-Nieto E, Perales-Vargas-Machuca JA (2012) Microbial degradation of PAHs: organisms and environmental compartments. Microbial Degradation of Xenobiotics. Springer.

Ron EZ, Rosenberg E (2014) Enhanced bioremediation of oil spills in the sea. Curr Opin Biotechnol 27: 191-194.

Saison C, Perrin-Ganier C, Amellal S, Morel J-L, Schiavon M (2004) Effect of metals on the adsorption and extractability of 14C-phenanthrene in soils. Chemosphere 55: 477485.

Santos DKF, Rufino RD, Luna JM, Santos VA, Sarubbo LA (2016) Biosurfactants: multifunctional biomolecules of the 21st century. Int J Mol Sci 17: 401.

Sasse J, Martinoia E, Northen T (2018) Feed your friends: do plant exudates shape the root microbiome? Trends Plant Sci 23: 25-41.

Saum L, Jiménez MB, Crowley D (2018) Influence of biochar and compost on phytoremediation of oil-contaminated soil. Int J Phytoremediation 20: 54-60.

Schandry N, Becker C (2019) Allelopathic Plants: Models for Studying Plant-Interkingdom Interactions. Trends Plant Sci.

Schwarzenbach RP, Gschwend PM, Imboden DM (2016) Environmental organic chemistry. John Wiley \& Sons.

Segura A, Ramos JL (2013) Plant-bacteria interactions in the removal of pollutants. Curr Opin Biotechnol 24: 467-473.

Segura A, Rodríguez-Conde S, Ramos C, Ramos JL (2009) Bacterial responses and interactions with plants during rhizoremediation. Microb Biotechnol 2: 452-464. 
Shabir G, Arslan M, Fatima K, Amin I, Khan QM, Afzal M (2016) Effects of inoculum density on plant growth and hydrocarbon degradation. Pedosphere 26: 774-778.

Shahi A, Aydin S, Ince B, Ince O (2016) Evaluation of microbial population and functional genes during the bioremediation of petroleum-contaminated soil as an effective monitoring approach. Ecotoxicol Environ Saf 125: 153-160.

Shahzad A, Saddiqui S, Bano A (2016) The response of maize (Zea mays L.) plant assisted with bacterial consortium and fertilizer under oily sludge. Int J Phytoremediation 18: $521-526$.

Siciliano SD, Fortin N, Mihoc A, Wisse G, Labelle S, Beaumier D, Ouellette D, Roy R, Whyte LG, Banks MK (2001) Selection of specific endophytic bacterial genotypes by plants in response to soil contamination. Appl Environ Microbiol 67: 2469-2475.

Sillen WM, Thijs S, Abbamondi GR, Janssen J, Weyens N, White JC, Vangronsveld J (2015) Effects of silver nanoparticles on soil microorganisms and maize biomass are linked in the rhizosphere. Soil Biol Biochem 91: 14-22.

Singer AC, Crowley DE, Thompson IP (2003) Secondary plant metabolites in phytoremediation and biotransformation. Trends Biotechnol 21: 123-130.

Sipilä TP, Keskinen A-K, Åkerman M-L, Fortelius C, Haahtela K, Yrjälä K (2008) High aromatic ring-cleavage diversity in birch rhizosphere: $\mathrm{PAH}$ treatment-specific changes of IE 3 group extradiol dioxygenases and 16S rRNA bacterial communities in soil. ISME J 2: 968.

Sivaram AK, Logeshwaran P, Lockington R, Naidu R, Megharaj M (2018) Impact of plant photosystems in the remediation of benzo [a] pyrene and pyrene spiked soils. Chemosphere 193: 625-634.

Smułek W, Sydow M, Zabielska-Matejuk J, Kaczorek E (2020) Bacteria involved in biodegradation of creosote $\mathrm{PAH}-\mathrm{A}$ case study of long-term contaminated industrial area. Ecotoxicol Environ Saf 187: 109843.

Sobolewska D, Michalska K, Podolak I, Grabowska K (2016) Steroidal saponins from the genus Allium. Phytochem Rev 15: 1-35.

Soleimani M, Afyuni M, Hajabbasi MA, Nourbakhsh F, Sabzalian MR, Christensen JH (2010) Phytoremediation of an aged petroleum contaminated soil using endophyte infected and non-infected grasses. Chemosphere 81: 1084-1090.

Song Y, Li Y, Zhang W, Wang F, Bian Y, Boughner LA, Jiang X (2016) Novel biochar-plant tandem approach for remediating hexachlorobenzene contaminated soils: proof-ofconcept and new insight into the rhizosphere. J Agric Food Chem 64: 5464-5471.

Sousa RMS, Mendes LW, Antunes JEL, de Souza Oliveira LM, Sousa AMdCB, Gomes RLF, de Almeida Lopes AC, Araújo FF, Melo VMM, Araujo ASF (2020) Diversity and structure of bacterial community in rhizosphere of lima bean. Appl Soil Ecol: 103490.

Staninska-Pięta J, Piotrowska-Cyplik A, Juzwa W, Zgoła-Grześkowiak A, Wolko Ł, Sydow Z, Kaczorowski Ł, Powierska-Czarny J, Cyplik P (2019) The impact of natural and synthetic surfactants on bacterial community during hydrocarbon biodegradation. Int Biodeterior Biodegrad 142: 191-199.

Steliga T, Kluk D (2020) Application of Festuca arundinacea in phytoremediation of soils contaminated with $\mathrm{Pb}, \mathrm{Ni}, \mathrm{Cd}$ and petroleum hydrocarbons. Ecotoxicol Environ Saf 194: 110409.

Stringlis IA, Yu K, Feussner K, de Jonge R, Van Bentum S, Van Verk MC, Berendsen RL, Bakker PA, Feussner I, Pieterse CM (2018) MYB72-dependent coumarin exudation shapes root microbiome assembly to promote plant health. Proc Natl Acad Sci USA 115: E5213-E5222.

Stroud J, Paton G, Semple KT (2007) Microbe-aliphatic hydrocarbon interactions in soil: implications for biodegradation and bioremediation. J Appl Microbiol 102: 12391253.

Sun B, Gao Y, Liu J, Sun Y (2012) The impact of different root exudate components on phenanthrene availability in soil. Soil Sci Soc Am J 76: 2041-2050. 
Sun R, Belcher RW, Liang J, Wang L, Thater B, Crowley DE, Wei G (2015) Effects of cowpea (Vigna unguiculata) root mucilage on microbial community response and capacity for phenanthrene remediation. J Environ Sci (China) 33: 45-59.

Sun T-R, Cang L, Wang Q-Y, Zhou D-M, Cheng J-M, Xu H (2010) Roles of abiotic losses, microbes, plant roots, and root exudates on phytoremediation of PAHs in a barren soil. J Hazard Mater 176: 919-925.

Técher D, Laval-Gilly P, Henry S, Bennasroune A, Formanek P, Martinez-Chois C, D'Innocenzo M, Muanda F, Dicko A, Rejšek K (2011) Contribution of Miscanthus X giganteus root exudates to the biostimulation of PAH degradation: An in vitro study. Sci Total Environ 409: 4489-4495.

Teng Y, Shen Y, Luo Y, Sun X, Sun M, Fu D, Li Z, Christie P (2011) Influence of Rhizobium meliloti on phytoremediation of polycyclic aromatic hydrocarbons by alfalfa in an aged contaminated soil. J Hazard Mater 186: 1271-1276.

Thijs S, Sillen W, Rineau F, Weyens N, Vangronsveld J (2016) Towards an enhanced understanding of plant-microbiome interactions to improve phytoremediation: engineering the metaorganism. Front Microbiol 7: 341.

Thomas F, Corre E, Cebron A (2019) Stable isotope probing and metagenomics highlight the effect of plants on uncultured phenanthrene-degrading bacterial consortium in polluted soil. ISME J 13: 1814-1830.

Thomas JC, Russell DK, Rugh CL (2017) Polyaromatic hydrocarbon phytoremediation stimulated by root exudates. Int J Environ Bioremediat Biodegr 5: 1-7.

Toyama T, Furukawa T, Maeda N, Inoue D, Sei K, Mori K, Kikuchi S, Ike M (2011) Accelerated biodegradation of pyrene and benzo [a] pyrene in the Phragmites australis rhizosphere by bacteria-root exudate interactions. Water Res 45: 16291638.

Trindade P, Sobral L, Rizzo A, Leite S, Soriano A (2005) Bioremediation of a weathered and a recently oil-contaminated soils from Brazil: a comparison study. Chemosphere 58: 515-522.

Truskewycz A, Gundry TD, Khudur LS, Kolobaric A, Taha M, Aburto-Medina A, Ball AS, Shahsavari E (2019) Petroleum Hydrocarbon Contamination in Terrestrial Ecosystems-Fate and Microbial Responses. Molecules 24: 3400.

Turkovskaya O, Muratova A (2019) Plant-bacterial degradation of polyaromatic hydrocarbons in the rhizosphere. Trends Biotechnol 37: 926-930.

Tyagi M, da Fonseca MMR, de Carvalho CC (2011) Bioaugmentation and biostimulation strategies to improve the effectiveness of bioremediation processes. Biodegradation 22: 231-241.

Ueno A, Ito Y, Yumoto I, Okuyama $\mathrm{H}$ (2007) Isolation and characterization of bacteria from soil contaminated with diesel oil and the possible use of these in autochthonous bioaugmentation. World J Microbiol Biotechnol 23: 1739-1745.

Urum K, Grigson S, Pekdemir T, McMenamy S (2006) A comparison of the efficiency of different surfactants for removal of crude oil from contaminated soils. Chemosphere 62: $1403-1410$.

Varjani S, Thaker M, Upasani V (2014) Optimization of growth conditions of native hydrocarbon utilizing bacterial consortium "HUBC" obtained from petroleum pollutant contaminated sites. Indian J Appl Res 4: 474-476.

Varjani SJ (2017) Microbial degradation of petroleum hydrocarbons. Bioresour Technol 223: $277-286$.

Varjani SJ, Rana DP, Jain AK, Bateja S, Upasani VN (2015) Synergistic ex-situ biodegradation of crude oil by halotolerant bacterial consortium of indigenous strains isolated from on shore sites of Gujarat, India. Int Biodeterior Biodegrad 103: 116-124.

Vieira S, Sikorski J, Dietz S, Herz K, Schrumpf M, Bruelheide H, Scheel D, Friedrich MW, Overmann J (2020) Drivers of the composition of active rhizosphere bacterial communities in temperate grasslands. ISME J 14: 463-475. 
Vincken J-P, Heng L, de Groot A, Gruppen H (2007) Saponins, classification and occurrence in the plant kingdom. Phytochemistry 68: 275-297.

Vives-Peris V, de Ollas C, Gómez-Cadenas A, Pérez-Clemente RM (2019) Root exudates: from plant to rhizosphere and beyond. Plant Cell Rep: 1-15.

Wang M, Chen Y, Chen S, Chien SC, Sunkara S (2012) Phytoremediation of pyrene contaminated soils amended with compost and planted with ryegrass and alfalfa. Chemosphere 87: 217-225.

Wang W, Zhong R, Shan D, Shao Z (2014) Indigenous oil-degrading bacteria in crude oilcontaminated seawater of the Yellow sea, China. Appl Microbiol Biotechnol 98: 7253-7269.

Wei R, Ni J, Chen W, Yang Y (2017) Variation in soil aggregate-size distribution affects the dissipation of polycyclic aromatic hydrocarbons in long-term field-contaminated soils. Environ Sci Pollut Res 24: 22332-22339.

Wenzel WW (2009) Rhizosphere processes and management in plant-assisted bioremediation (phytoremediation) of soils. Plant Soil 321: 385-408.

Werner T, Motyka V, Strnad M, Schmülling T (2001) Regulation of plant growth by cytokinin. Proc Natl Acad Sci USA 98: 10487-10492.

White Jr P, Wolf D, Thoma G, Reynolds C (2003) Influence of organic and inorganic soil amendments on plant growth in crude oil-contaminated soil. Int J Phytoremediation 5: 381-397.

White PM, Wolf DC, Thoma GJ, Reynolds CM (2006) Phytoremediation of alkylated polycyclic aromatic hydrocarbons in a crude oil-contaminated soil. Water Air Soil Pollut 169: 207-220.

Wiszniewska A, Hanus-Fajerska E, MUSZYŃSKA E, Ciarkowska K (2016) Natural organic amendments for improved phytoremediation of polluted soils: a review of recent progress. Pedosphere 26: 1-12.

Wu N, Zhang S, Huang H, Christie P (2008) Enhanced dissipation of phenanthrene in spiked soil by arbuscular mycorrhizal alfalfa combined with a non-ionic surfactant amendment. Sci Total Environ 394: 230-236.

Xia M, Chakraborty R, Terry N, Singh RP, Fu D (2020) Promotion of saltgrass growth in a saline petroleum hydrocarbons contaminated soil using a plant growth promoting bacterial consortium. Int Biodeterior Biodegrad 146: 104808.

Xia M, Liu Y, Taylor AA, Fu D, Khan AR, Terry N (2017) Crude oil depletion by bacterial strains isolated from a petroleum hydrocarbon impacted solid waste management site in California. Int Biodeterior Biodegrad 123: 70-77.

Xun F, Xie B, Liu S, Guo C (2015) Effect of plant growth-promoting bacteria (PGPR) and arbuscular mycorrhizal fungi (AMF) inoculation on oats in saline-alkali soil contaminated by petroleum to enhance phytoremediation. Environ Sci Pollut Res 22: 598-608.

Yang J, Kloepper JW, Ryu C-M (2009) Rhizosphere bacteria help plants tolerate abiotic stress. Trends Plant Sci 14: 1-4.

Yang Y, Zhang N, Xue M, Lu S, Tao S (2011) Effects of soil organic matter on the development of the microbial polycyclic aromatic hydrocarbons (PAHs) degradation potentials. Environ Pollut 159: 591-595.

Yavari S, Malakahmad A, Sapari NB (2015) A review on phytoremediation of crude oil spills. Water, Air, Soil Pollut 226: 279.

Yergeau E, Sanschagrin S, Maynard C, St-Arnaud M, Greer CW (2014) Microbial expression profiles in the rhizosphere of willows depend on soil contamination. ISME J 8: 344.

Zhang J, Lin X, Liu W, Wang Y, Zeng J, Chen H (2012) Effect of organic wastes on the plant-microbe remediation for removal of aged PAHs in soils. J Environ Sci (China) 24: 1476-1482.

Zhao X, Yang J, Bai S, Ma F, Wang L (2016) Microbial population dynamics in response to bioaugmentation in a constructed wetland system under $10 \mathrm{C}$. Bioresour Technol 205: 166-173. 
Zhen M, Chen H, Liu Q, Song B, Wang Y, Tang J (2019) Combination of rhamnolipid and biochar in assisting phytoremediation of petroleum hydrocarbon contaminated soil using Spartina anglica. J Environ Sci (China) 85: 107-118.

Zhou W, Wang X, Chen C, Zhu L (2013) Enhanced soil washing of phenanthrene by a plant-derived natural biosurfactant, Sapindus saponin. Colloids Surf Physicochem Eng Aspects 425: 122-128. 


\section{List of Figures:}

Figure 1. Chemical classification of petroleum hydrocarbons (Coulon and $\mathrm{Wu}$, 2014)

Figure 2. Effect of some factors on the rhizoremediation of TPH-contaminated soils (A) plant species, (B) soil temperature, (C) microbial composition, and (D) hydrocarbon characteristics (carbon chain length)

Figure 3. Factors affecting the rhizoremediation of petroleum hydrocarbons 


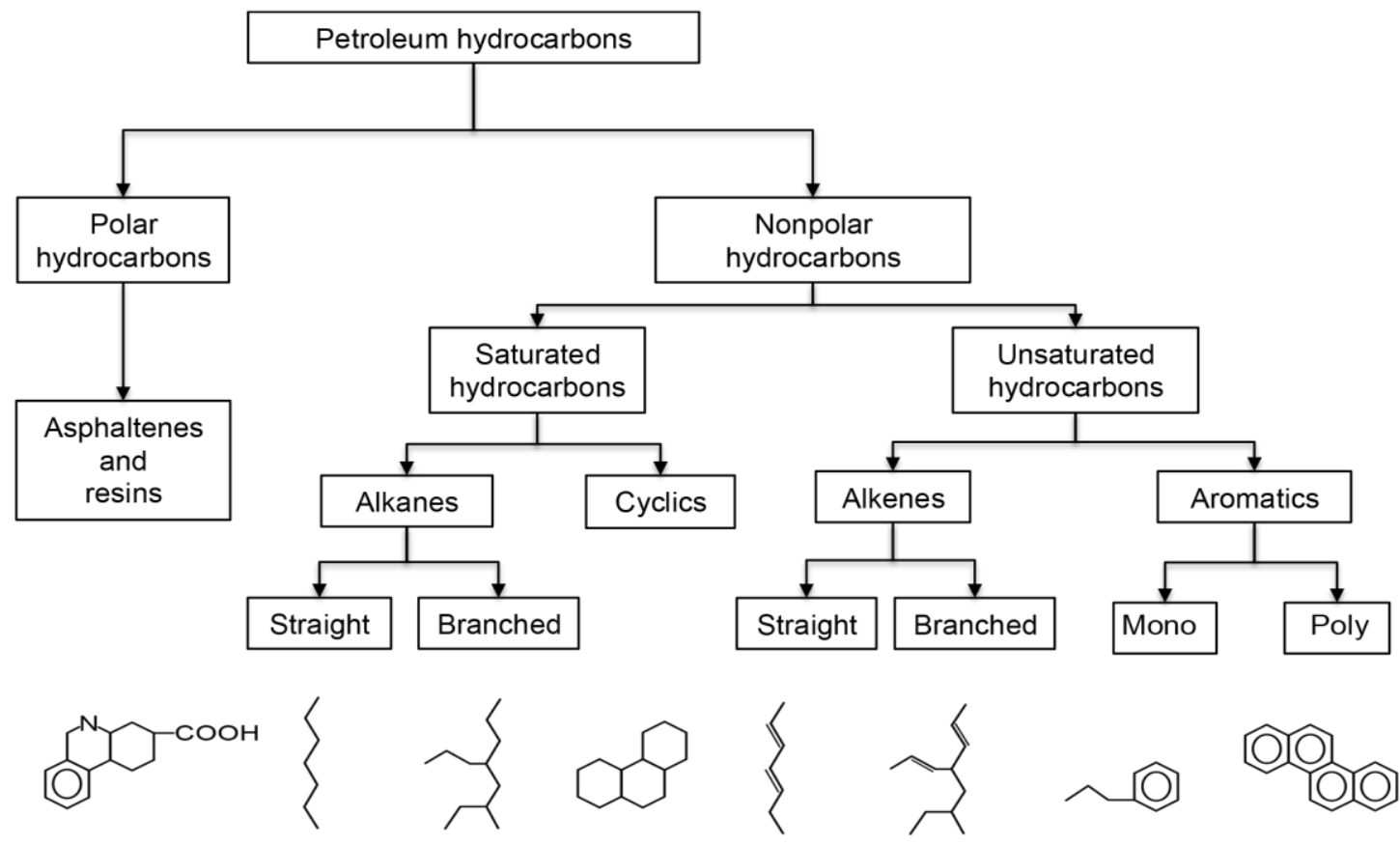

Figure 1. Chemical classification of petroleum hydrocarbons (Coulon and Wu, 2014) 


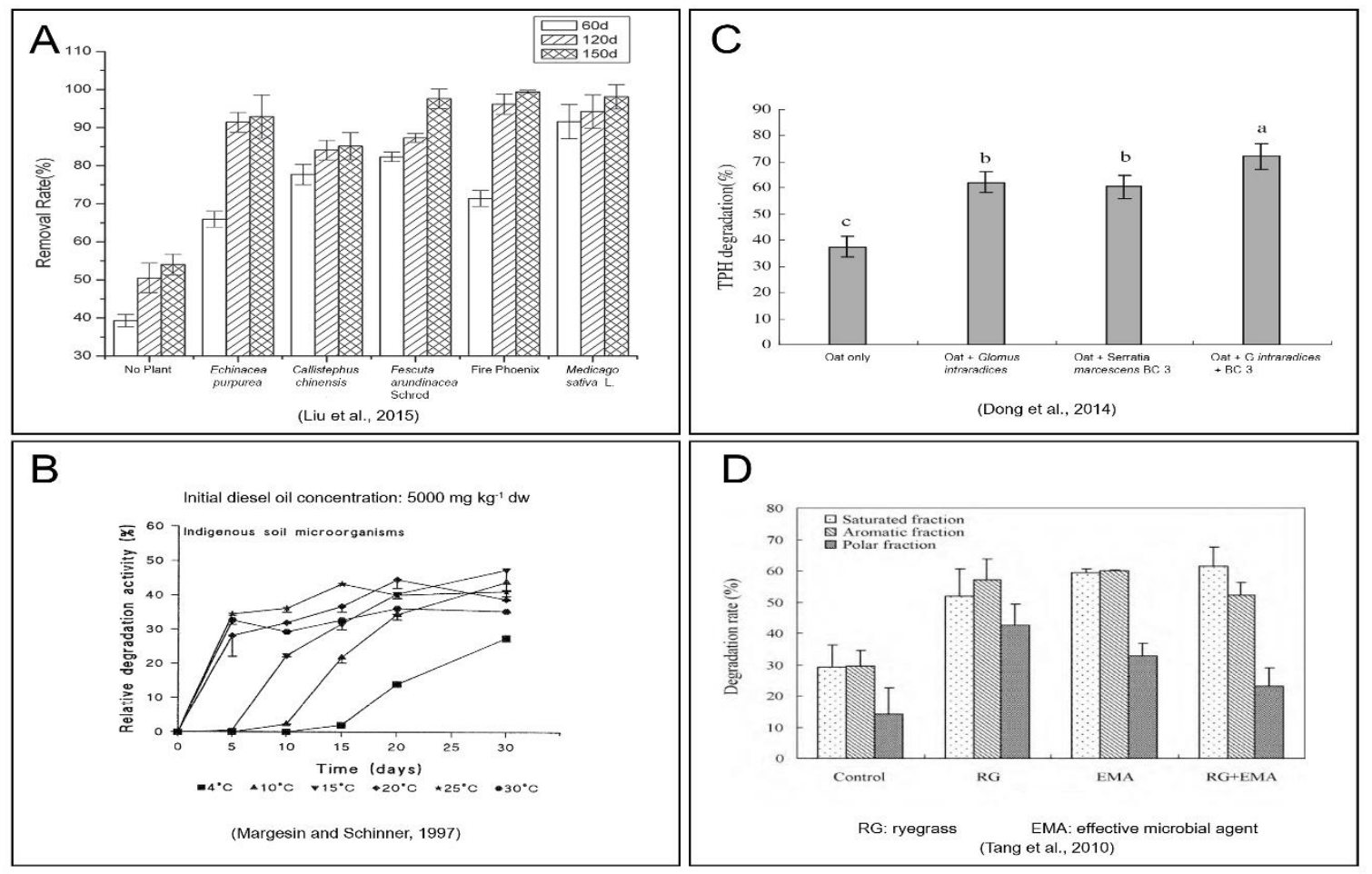

Figure 2. Effect of some factors on the rhizoremediation of TPH-contaminated soils (A) plant species, (B) soil temperature, (C) microbial composition, and (D) hydrocarbon characteristics (carbon chain length) 


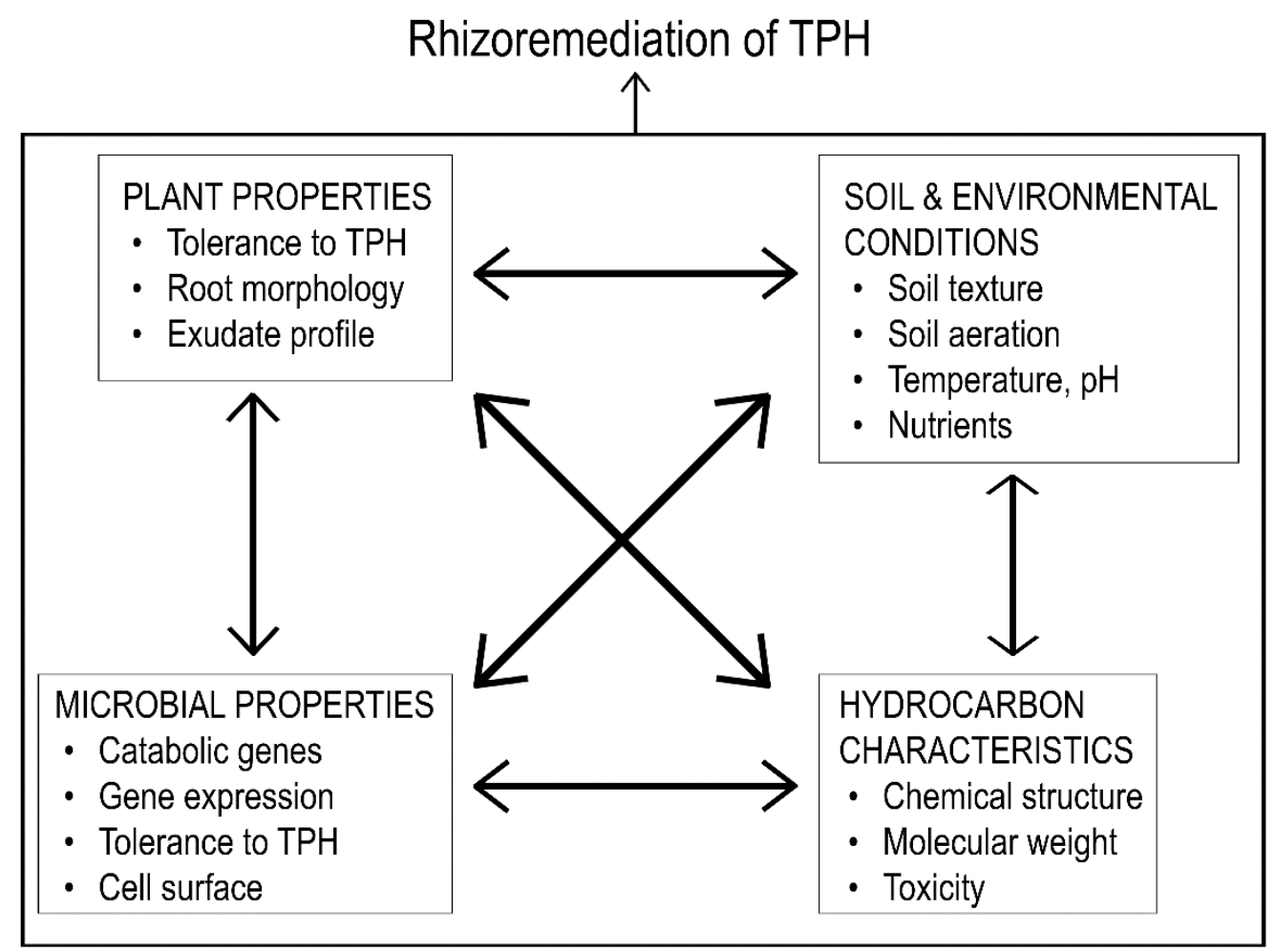

Figure 3. Factors affecting the rhizoremediation of petroleum hydrocarbons 
Table 1. Microbial enzymes with a role in degradation of organic compounds (adapted from Gerhardt et al. 2009)

\begin{tabular}{|c|c|c|}
\hline Enzyme family & Catalytic action & Examples of known sources \\
\hline Dehalogenase & $\begin{array}{l}\text { Hydrolyzes chlorine and } \\
\text { fluorine from halogenated } \\
\text { aliphatic hydrocarbons (e.g., } \\
\text { trichloroethylene) and } \\
\text { aromatic hydrocarbons (e.g., } \\
\text { PCBs, DDT) }\end{array}$ & $\begin{array}{l}\text { Bacteria: } \\
\text { Xanthobacter } \\
\text { autotrophicus } \\
\text { Sphingobium } \\
\text { chlorophenolicum } \\
\text { Plant: Hybrid poplar } \\
\text { (Populus spp.) }\end{array}$ \\
\hline Laccase & $\begin{array}{l}\text { Degradation of various aromatic } \\
\text { compounds }\end{array}$ & $\begin{array}{l}\text { Fungi: } \\
\text { Trametes versicolor } \\
\text { Coriolopsis polyzona } \\
\text { Plant: } \\
\text { Alfalfa (Medicago sativa) }\end{array}$ \\
\hline Dioxygenase & $\begin{array}{l}\text { Degradation of various aromatic } \\
\text { compounds }\end{array}$ & $\begin{array}{l}\text { Bacteria: } \\
\text { Pseudomonas sp. } \\
\text { Mycobacterium sp. }\end{array}$ \\
\hline Peroxidase & $\begin{array}{l}\text { Degradation of various aromatic } \\
\text { compounds; reductive } \\
\text { dehalogenation of aliphatic } \\
\text { hydrocarbons }\end{array}$ & $\begin{array}{l}\text { Fungi: } \\
\text { Phanerochaete } \\
\text { chrysosporidium } \\
\text { Phanerochaete laevis } \\
\text { Plant } \\
\text { Alfalfa (Medicago sativa) } \\
\text { Horseradish (Armoracia } \\
\text { rusticana) }\end{array}$ \\
\hline Nitrilase & $\begin{array}{l}\text { Cleaves cyanide groups from } \\
\text { aromatic and aliphatic nitriles }\end{array}$ & $\begin{array}{l}\text { Fungi: } \\
\text { Aspergillus niger } \\
\text { Plant: } \\
\text { Willow (Salix spp.) }\end{array}$ \\
\hline Nitroreductase & $\begin{array}{l}\text { Reduces nitro groups on } \\
\text { nitroaromatic compounds } \\
\text { (e.g., 2,4,6-trinitrotoluene); removes } \mathrm{N} \\
\text { from ring structures }\end{array}$ & $\begin{array}{l}\text { Bacteria: } \\
\text { Comamonas sp. } \\
\text { Pseudomonas putida } \\
\text { Plant: } \\
\text { Hybrid poplar (Populus } \\
\text { spp.) }\end{array}$ \\
\hline Phosphatase & $\begin{array}{l}\text { Cleaves phosphate groups } \\
\text { from organophosphates } \\
\text { (e.g., pesticides) }\end{array}$ & $\begin{array}{l}\text { Plant: } \\
\text { Giant duckweed (Spirodela } \\
\text { polyrhiza) }\end{array}$ \\
\hline $\begin{array}{l}\text { Cytochrome } \\
\text { P450 }\end{array}$ & $\begin{array}{l}\text { Hydroxylation of aromatic } \\
\text { and aliphatic hydrocarbons }\end{array}$ & $\begin{array}{l}\text { Most aerobic bacteria, all fung } \\
\text { and all plants }\end{array}$ \\
\hline
\end{tabular}


Table 2. Summary of biostimulation-assisted rhizoremediation in $\mathrm{TPH}$-contaminated soils

\begin{tabular}{|c|c|c|}
\hline Host plant(s) & Type of supplement(s) & Contaminant types \& levels \\
\hline $\begin{array}{l}\text { Spartina alterniflora } \\
\text { (Smooth cord grass) } \\
\text { Spartina patens } \\
\text { (Saltmeadow cord grass) }\end{array}$ & $\begin{array}{l}\mathrm{N}-\mathrm{P}-\mathrm{K} \text { fertilizer }\left(\mathrm{N}-\mathrm{NH}_{4}: 666 \mathrm{~kg}\right. \\
\mathrm{N} \mathrm{ha}{ }^{-1}, \mathrm{P}_{-} \mathrm{P}_{2} \mathrm{O}_{5}: 272 \mathrm{~kg} \mathrm{P} \mathrm{ha}^{-1} \text {, } \\
\left.\mathrm{K}-\mathrm{K}_{2} \mathrm{O}: 514 \mathrm{~kg} \mathrm{~K} \mathrm{ha}^{-1}\right) \text { was } \\
\text { applied in oil contaminated } \\
\text { soils. }\end{array}$ & $\begin{array}{l}\text { South Louisiana crude oil. } \\
\text { Four levels of oil in soil: no } \\
\text { oil, medium oil ( } 20-50 \mathrm{mg} \mathrm{g}^{-} \\
\left.{ }^{1}\right) \text {, heavy oil }\left(70-150 \mathrm{mg} \mathrm{g}^{-1}\right) \text {, } \\
\text { and very heavy oil }(>200 \mathrm{mg} \\
\left.\mathrm{g}^{-1}\right) \text {. }\end{array}$ \\
\hline $\begin{array}{l}\text { Cyperus brevifolius } \\
\text { (Rottb.) Hassk }\end{array}$ & 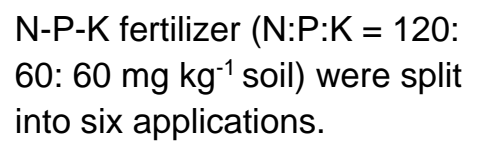 & $\begin{array}{l}\text { Soil was mixed by hand with } \\
\text { crude oil at the concentration } \\
\text { of } 80,000 \mathrm{mg} \mathrm{kg}^{-1} \text { dry soil. }\end{array}$ \\
\hline $\begin{array}{l}\text { Lolium multiflorum Lam. } \\
\text { (Ryegrass) }\end{array}$ & $\begin{array}{l}\text { Inorganic controlled release } \\
\text { fertilizer CRF (15N-3.9P-9.9K) } \\
\text { was incorporated into } \\
\text { contaminated soil at } 4,6,8 \mathrm{~kg} \\
\mathrm{~m}^{-3} \text { (low, medium, and high) }\end{array}$ & $\begin{array}{l}\text { Weathered Arabian medium } \\
\text { crude oil (petroleum) was } \\
\text { mixed with air-dried soil at } \\
3000,6000,15000 \mathrm{mg} \mathrm{kg}^{-1} \\
\text { (low, medium, and high) }\end{array}$ \\
\hline $\begin{array}{l}\text { Penninsetum purpureum } \\
\text { (Elephant grass) }\end{array}$ & 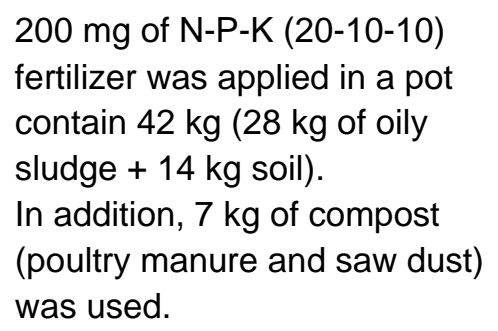 & $\begin{array}{l}\text { TPH value of the oily sludge- } \\
\text { soil mixture was } 64,494 \mathrm{mg} \\
\mathrm{kg}^{-1} \text {. }\end{array}$ \\
\hline
\end{tabular}

S.alterniflora and S.patens can tolerate with oil concentration as high as 100 and $250 \mathrm{mg} \mathrm{g}^{-1}$, respectively.

Fertilizers application increased both biomass of both plant species and oil degradation rate.

Fertilizing showed significant enhancement of plant biomass during the first 60 days.

The degradation of total oil and grease in crude oil-impacted soil in the presence of C.brevifolius was significantly enhanced in fertilized treatment.

The application of CRF in contaminated soil enhanced plant adaption, growth, photosynthesis, and chlorophyll content of the plant in petroleum impacted soil.

Rhizoremediation efficiencies of medium and high petroleum concentrations were stimulated by the application of medium rates of CRF. TPH removal rate was $69 \%$ in the combination between elephant grass and NPK fertilizer (phytoremediation), whereas those values in composting treatment alone and in (phytoremediation + composting) treatment were $47 \%$ and $29 \%$, respectively. Total heterotrophic bacterial was also highest in phytoremediation treatment.
Lin and

Mendelssohn

(1998)

Basumatary

et al. (2012)

Cartmill et al 
Brachiaria brizantha

(Tropical pasture grass)

Megathyrsus maximus (Guinea grass)

Prosopis articulate (Mesquite shrubs)

\section{Hordum vulgare}

(Barley)

Avena sativa

(Oat)
N-P-K fertilizer (20-20-20) was added to contaminated soil at different levels: 200, 300, and $400 \mathrm{mg} \mathrm{kg}^{-1}$ (low, medium, and high)

Spent mushroom compost (SMC) was mixed in $5 \mathrm{~kg}$ contaminated soil with different concentrations: 10 , 20,30 , and $40 \%(w / w)$.

\section{Compost consisted of} cruciferous waste and daily cow manure at a ratio of $1: 2$ (w/w) was mixed with motor oil contaminated soil at $5 \%(\mathrm{w} / \mathrm{w})$. Biochar produced by pyrolysis at $350^{\circ} \mathrm{C}$ for $4 \mathrm{~h}$ using corn stalks as feedstock was added to motor oil contaminated soil at $1.5 \%(\mathrm{w} / \mathrm{w})$.

Biochar was produced from poultry manure at $400^{\circ} \mathrm{C}$ for $4 \mathrm{~h}$ in a furnace.

Two biochar levels ( 0 and $1 \%$ ) (w/w) were applied.
Soil was artificially contaminated with $5 \%(\mathrm{w} / \mathrm{w})$ of a heavy crude oil.

Contaminated soil sample was collected from a mechanic site.

The soil was heavily contaminated with high concentrations of metals and 5 and 6-ring PAHs.

Contaminated soil was prepared by mixing used automobile motor oil with uncontaminated soil at $2 \%$ $(w / w)$.

Soil samples were collected from two locations in an oil field and mixed with different ratios to prepare $3 \mathrm{TPH}$ contamination levels: 4, 6 , and $8 \%(\mathrm{w} / \mathrm{w})$.
Degradation of crude oil was higher in planted than in unplanted soil.

The medium fertilizer application resulted in highest plant biomass and oil dissipation in rhizoremediation approach over 22 weeks. During 120 day period, SMC treatments showed increased biomass and photosynthetic rates of the plant grown in impacted soil compared to plant alone. Besides, root and shoot anatomical responses were also enhanced.

SMC application in contaminated soils stimulated the degradation of hydrocarbon in the rhizosphere of $M$. maximus

The plant performance and TPH removal efficiencies were directly proportional to SMC concentrations.

In 105 day experiment, the addition of compost or biochar alone, or in combination all yielded plant with shorter taproots compared to noamended control.

Biochar used as the sole amendment reduced the population size of oil-degrading community Saum et al and petroleum bioavailability.

Addition of compost enhanced the extent of oil degradation ( $44 \%$ of the light hydrocarbon fraction).

After 140 days, plant yield cultivated in TPHimpacted soil treated with biochar was higher than that in soil without biochar.

On average, microbial respiration rate in the (2017)

Merkl et al (2005a)

Asemoloye et al. (2017) rhizosphere of oat and barley amended with 
A commercial biosurfactant (rhamnolipid JBR 210) was

Helianthus annuus L. (Sunflower)

Lolium multiflorum Lam. (Ryegrass) yield an initial surfactant

Alkali lignin (Sigma-Aldrich) was spiked into $\mathrm{PAH}$ contaminated soil at a concentration of $1 \%(w / w)$. mixture of mono- and di-
Soil sample was collected from a chronic multicontaminated (petroleum hydrocarbons + heavy metals) site.

mixed to contaminated soil to TPH value was $18.1 \mathrm{~g} \mathrm{~kg}^{-1}$, concentration of $4 \mathrm{mg} \mathrm{kg}^{-1}$ soil. approx. $70 \%$ in the range of lubricating oil (>C20), and high concentrations of vanadium, nickel, lead, chromium, and zinc. Commercial rhamnolipid $(90 \%$ rhamnolipid, critical micelle concentration (CMC) $50 \mathrm{mg} \mathrm{l}^{-1}$ was added to the soil to prepare a final concentration of $125 \mathrm{mg} \mathrm{kg}^{-1}$.

Soil used in this study was collected in a farmland. 47.1\% 4-ring, 28.7\% 5-ring, and $13 \% 6$-ring PAHs. biochar remarkably enhanced by 45.18 and $37.7 \%$ compared to non-biochar treatments. Biochar amendment resulted in higher TPH degradation rates in contaminated soils cultivated with both barley and oat (21.76 and $20.36 \%$, respectively higher than those in nonbiochar treatments).

TPH and PAH removal rates were highest in the treatment of co-contaminated soil supplemented with biosurfactant and cultivated with sunflower (58 and $48 \%$, respectively).

Significant reductions in the concentrations of heavy metals were also achieved.

Biosurfactant showed little effect on the structural of the dominant bacterial community in the rhizosphere soils of the plant.

Lignin was capable of stimulating microbial degradation of PAHs in the rhizosphere of the test plant and modifying the microbial community.

$\mathrm{PAH}$ value was $8.59 \mathrm{mg} \mathrm{kg}^{-1}$ soil, consisted of $11 \%$ 3-ring,

Rhamnolipid supported bacterial growth in soil and had a little influence on plant growth.

On average, rhizoremediation of PAHs with ryegrass amended by alkali lignin and rhamnolipid reduced PAH concentration by $41.7 \%$ while no reduction was observed when each treatment was used alone after 90 days.
Liduino et al.

Wu et al. 
Table 3. Examples of surfactant-like compounds from plant species from different studies

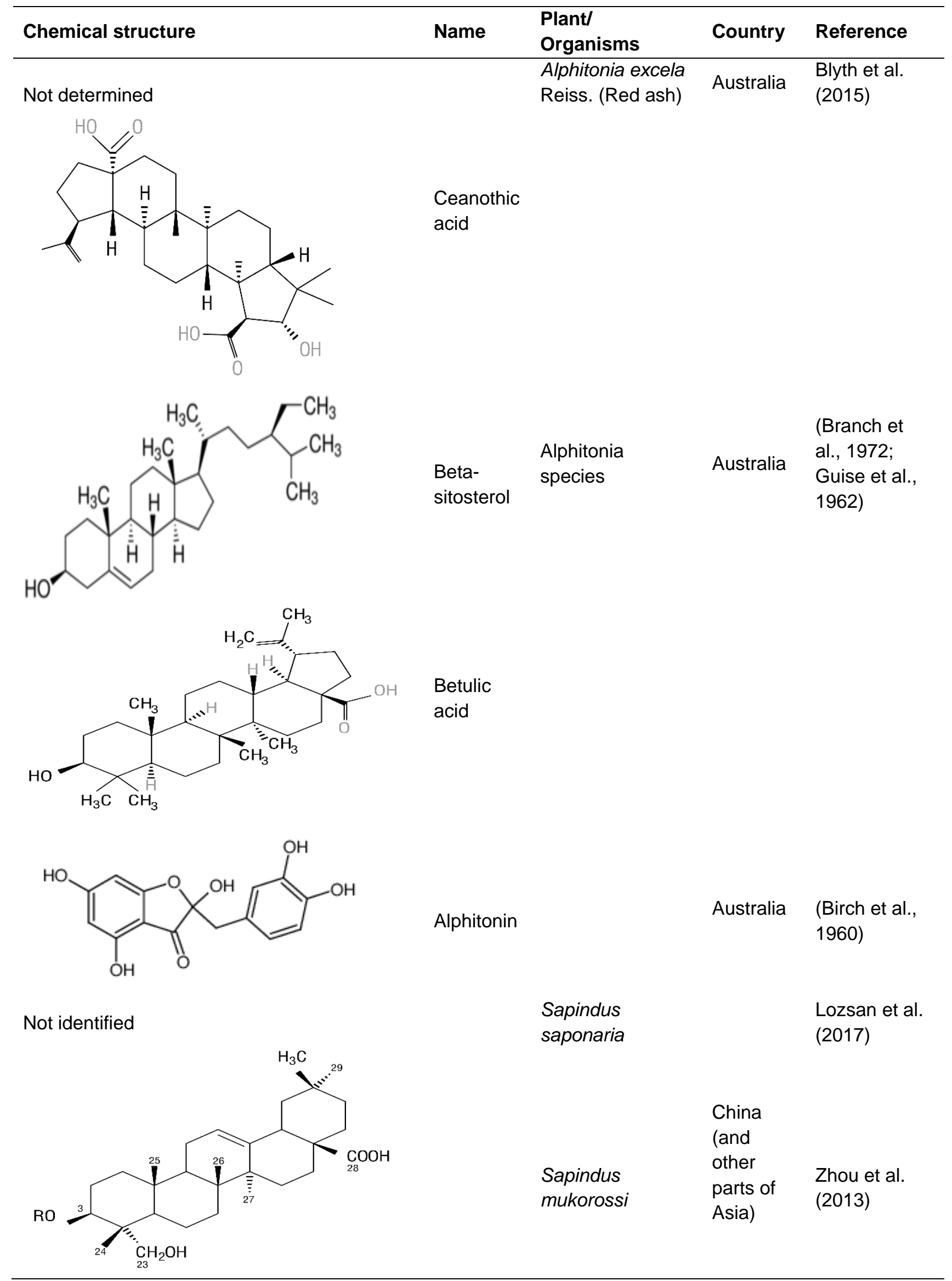


1 Table 4. Summary of bioaugmented amendments used to enhance rhizoremediation

2 efficiency in TPH-impacted soil

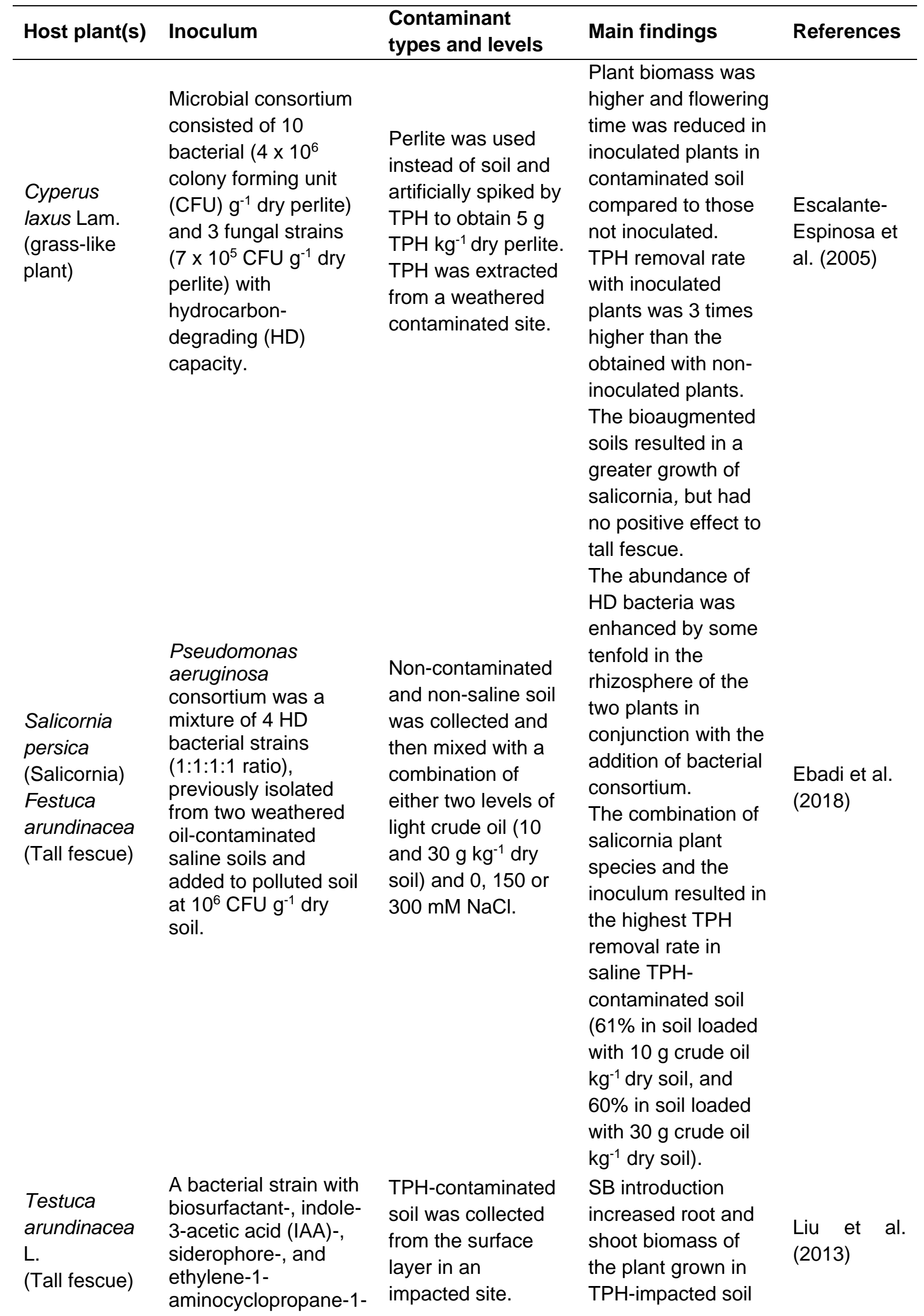




\begin{tabular}{|c|c|c|c|c|}
\hline & $\begin{array}{l}\text { carboxylic (ACC) } \\
\text { deaminase- } \\
\text { producing ability } \\
\text { (Pseudomonas sp. } \\
\text { SB) was isolated from } \\
\text { the rhizosphere of tall } \\
\text { fescue naturally } \\
\text { grown in a TPH- } \\
\text { contaminated soil and } \\
\text { added to the oily } \\
\text { sludge-contaminated } \\
\text { soil at } 5 \times 10^{9} \text { CFU kg- } \\
1 \text { dry soil. }\end{array}$ & $\begin{array}{l}\text { TPH value of the } \\
\text { soil before } \\
\text { remediation is } \\
1,851 \mathrm{mg} \mathrm{kg}^{-1} \text { dry } \\
\text { soil. }\end{array}$ & $\begin{array}{l}\text { by } 19 \text { and } 28 \% \text {, } \\
\text { respectively. } \\
\text { Over } 120 \text { days, the } \\
\text { reduction of both } \\
\text { TPH and PAH } \\
\text { content in soil had } \\
\text { the highest values } \\
\text { ( } 84.5 \text { and } 46.2 \% \text {, } \\
\text { respectively) in (tall } \\
\text { fescue + SB) } \\
\text { treatment. }\end{array}$ & \\
\hline $\begin{array}{l}\text { Melia } \\
\text { azadirachta } \\
\text { (Syringa } \\
\text { berrytree) }\end{array}$ & $\begin{array}{l}\text { After being isolated } \\
\text { from petroleum } \\
\text { contaminated sites } \\
\text { and then screened for } \\
\text { survival in B[a]P as } \\
\text { their sole source of } \mathrm{C} \text {, } \\
\text { two bacterial strains } \\
\text { with biosurfactant- } \\
\text { producing ability } \\
\text { (Bacilus flexus S1I26 } \\
\text { and Paenibacillus sp } \\
\text { S1I8) were chosen. } \\
\text { For each strain, } 5 \text { ml } \\
\text { cell suspension with } \\
\text { optical density } \\
\text { measured by } \\
\text { spectrophotometer at } \\
600 \text { nm (O.P. } 600= \\
0.5) \text { was added pots } \\
\text { containing } \\
\text { M.azadirachta and1 } \\
\text { kg B[a]P } \\
\text { contaminated soils. }\end{array}$ & $\begin{array}{l}\text { The contaminated } \\
\text { soil was prepared } \\
\text { by artificially spiking } \\
\mathrm{B}[\mathrm{a}] \mathrm{P} \text { to obtain the } \\
\text { initial concentration } \\
\text { of } 50 \mathrm{mg} \mathrm{kg}^{-1} \text { dry } \\
\text { soil. }\end{array}$ & $\begin{array}{l}\text { The isolates } \\
\text { produced surfactin } \\
\text { which could } \\
\text { solubilize B[a]P } \\
\text { efficiently } \\
\text { After } 60 \text { days, } \\
\text { bioaugmentation of } \\
\text { S1I8 and S1I26 } \\
\text { resulted in better } \\
\text { degradation of B[a]P } \\
\text { in the rhizosphere of } \\
\text { M.azadirachta } \\
\text { (87.42 and } 86.08 \% \text {, } \\
\text { respectively) } \\
\text { compared to non- } \\
\text { inoculated treatment } \\
\text { (83.5\%), and that in } \\
\text { non-rhizosphere } \\
\text { (bulk) soil (68.22\%). }\end{array}$ & $\begin{array}{l}\text { Kotoky and } \\
\text { Pandey } \\
(2019)\end{array}$ \\
\hline $\begin{array}{l}\text { Distichlis } \\
\text { spicata } \\
\text { (Saltgrass) }\end{array}$ & $\begin{array}{l}\text { A consortium consists } \\
\text { of five bacterial } \\
\text { strains } \\
\text { (Pseudomonas sp. } \\
\text { PFS1 and BSS3B2, } \\
\text { Serratia } \\
\text { proteamaculans } \\
\text { S1BD1, Alcaligenes } \\
\text { sp. PKS1, and } \\
\text { Bacillus sp. PSS2) } \\
\text { with different plant } \\
\text { growth-promoting } \\
\text { traits (phosphate } \\
\text { solubilisation, IAA, } \\
\text { and siderophore } \\
\text { production) were } \\
\text { used. }\end{array}$ & $\begin{array}{l}\text { Contaminated soil } \\
\text { sample was } \\
\text { collected from a } \\
\text { solid waste } \\
\text { management unit } \\
\text { with TPH value of } \\
15,000 \mathrm{mg} \mathrm{kg}^{-1} \mathrm{dry} \\
\text { soil and some } \\
\text { content of heavy } \\
\text { metals. }\end{array}$ & $\begin{array}{l}\text { Bacterial inoculation } \\
\text { significantly } \\
\text { enhanced plant } \\
\text { biomass in the } \\
\text { contaminated soil } \\
\text { (4- and 6-fold in } \\
\text { sterilized and non- } \\
\text { sterilized soil, } \\
\text { respectively) } \\
\text { compared to non- } \\
\text { inoculated } \\
\text { treatment. }\end{array}$ & $\begin{array}{l}\text { Xia et al. } \\
(2020)\end{array}$ \\
\hline $\begin{array}{l}\text { Zea may L. } \\
\text { (Maize) }\end{array}$ & $\begin{array}{l}\text { Bacillus subtilis } \\
\text { PM32Y and seven } \\
\text { bacterial strains } \\
\text { having plant growth } \\
\text { promotion and HD }\end{array}$ & $\begin{array}{l}\text { Non-contaminated } \\
\text { and sterilized sand } \\
\text { was artificially } \\
\text { spiked by crude oil } \\
\text { to obtain } 10 \mathrm{~g} \text { oil }\end{array}$ & $\begin{array}{l}\text { After } 60 \text { days of } \\
\text { planting in TPH- } \\
\text { contaminated soil, } \\
\text { Z.mays bio- } \\
\text { augmented with }\end{array}$ & $\begin{array}{l}\text { Asghar et al. } \\
(2017)\end{array}$ \\
\hline
\end{tabular}




potential were
isolated from
petroleum
contaminated soil
samples and
prepared in solution
at $10^{8}-10^{9} \mathrm{CFU} \mathrm{\textrm {ml } ^ { - 1 }}$
(inoculum) for each
strain.
Seeds were
inoculated by
dressing with different
inoculum before
sowing in $10 \mathrm{~kg}$
contaminated sand
pots.

$T$.

arundinacea

$\mathrm{L}$.

(Tall fescue)

Lolium

perenne

(Ryegrass)

pots.
Plant growth

promoting

rhizobacteria strains

Klebsiella sp. D5A

and Pseudomonas

sp. SB were prepared

to form two inocula

with a density of $10^{9}$

CFU ml-1 for each

strain.

$15 \mathrm{~mL}$ of each inocula

was mixed with

contaminated soil

before planting.

\section{Rhodococcus}

erythropolis CD 106

strain was isolated

from highly

petroleum-

contaminated site

showing several PGP

traits and $\mathrm{HC}$ and

biosurfactant-

producing ability.

After 4 weeks, CD106

was added to soil at

$10^{8}$ cells $\mathrm{g}^{-1}$ dry soil.

(TPH) per kg of sand.

Weathered

contaminated soil, collected near an oil production site had initial TPH value of $4407 \mathrm{mg} \mathrm{kg}^{-1}$ dry soil, and then amended with inorganic nutrients for

rhizoremediation.

\section{Petroleum-} contaminated soil was collected from a 100-year-old oil refinery which had TPH value of 9396 $\pm 124 \mathrm{mg} \mathrm{kg}^{-1}$ dry soil.
PM32Y exhibited the most significant increase in plant growth among 8 bacterial strains (75\% in root length, $74 \%$ in plant height, and $67 \%$ in plant biomass compared to un-inoculated treatment).

Maize in association with PM32Y application had the highest efficiency in reducing $\mathrm{TPH}$ concentration compared to other bacterial introduction as well as un-inoculated treatment.

After 4 months, in both two inoculation treatments, tall fescue biomass increased by PGPR. The highest levels of TPH removal were reported in two Hou et al. PGPR inoculation. The removal efficiency was relative to specific bacterial communities, but not to bacterial diversity.

Fresh shoot and root biomass of ryegrass was enhanced by 49 and $30 \%$, respectively by the introduction of CD 106 compared to those in non-inoculated treatment.

After 210 days, the combination between ryegrass and CD 106
(2015)

Płociniczak

et al. (2017) 
TPH-degrading microbial strains of Bacillus subtilis, Sphingobacterium multivolume,

Acinetobacter radioresistens, Rhodococcus

Lolium perenne (Ryegrass)

Avena sativa (Oat) erythropolis, and Pseudomonas fluorescens were isolated from an oil field and incubated in liquid media at over $10^{10} \mathrm{CFU} \mathrm{g}^{-1}$ used both as single or mixed agent to mix in impacted soil at the rate of $1: 4(w / w)$.

The AMF used was Glomus intraradices and prepared in a mixture of rhizospheric soil from affalfa consisting of spores, hyphae, and mycorrhizal root fragments and added to contaminated soil at $5 \%(\mathrm{v} / \mathrm{v})$. The bacterial strain was Serratia marcescens BC-3, isolated from a petroleum contaminated site with ACC deaminaseproducing ability and prepared in

reduced TPH

concentration by

$31.2 \%$. On the

contrary, the

concentration of

TPH was decreased

by $16.8 \%$ in non-

inoculated soil.

The addition of CD

106 had limited

impacted on

autochthonous

microflora during the

experiment.

The combination of ryegrass with the mixture of 4

Petroleumcontaminated soil was collected from an oil field with TPH content of $6.19 \%$.

Constituents of TPH are: $50.5 \%$ saturated hydrocarbons, $20.8 \%$ aromatic hydrocarbons, and $27.7 \%$ asphatene and polar fraction.

Petroleum was added to uncontaminated soil at $3.5 \mathrm{~g} \mathrm{~kg}^{-1}$ dry soil to prepare TPHcontaminated soil for this experiment. bacteria: B.subtilis S.multivolume, $A$. radioresistens, and R.erythropolis resulted in the highest degradation rate of $58 \%$ after 162 days.

The mixing of 4 strains also yielded the highest biomass in TPHcontaminated soil compared to other (non-inoculated or single-strain) treatments.

TPH hindered oat growth; however, the co-inoculation of G.intraradices and S. marcescens BC3 significantly decrease this suppression (plant growth showed the quite same value to those in noncontaminated soil). The introduction of either G.intraradices or $S$. marcescens BC-3 also increased soil microbial activity, and TPH
Tang et al.

(2010)

Dong et al.

(2014) 


\begin{tabular}{|c|c|c|c|c|}
\hline & $\begin{array}{l}\text { suspension at } 10^{9} \\
\text { CFU } \mathrm{ml}^{-1} \text {. } \\
\text { Seeds were } \\
\text { bacterized with the } \\
\text { suspension for } 2 \mathrm{~h} \text { and } \\
\text { dried. }\end{array}$ & & $\begin{array}{l}\text { removal rate (up to } \\
72 \% \text { ) in the } \\
\text { rhizosphere of oat. }\end{array}$ & \\
\hline $\begin{array}{l}\text { Zea may L. } \\
\text { (Maize) }\end{array}$ & $\begin{array}{l}\text { Five bacterial strains } \\
\text { were used in this } \\
\text { experiment namely } \\
\text { R4, R108 } \\
\text { (Pseudomonas } \\
\text { putida), P9, P12, and } \\
\text { R169 (Pseudomonas } \\
\text { fluorescens) were } \\
\text { isolated from a farm } \\
\text { soil for their ability to } \\
\text { produce IAA and ACC } \\
\text { deaminase. } \\
\text { Seeds were } \\
\text { immerged in bacterial } \\
\text { suspensions }(1 \text { ml per } \\
\text { seed with CFU }=10^{8} \\
\text { cell } \mathrm{ml}^{-1} \text { ). }\end{array}$ & $\begin{array}{l}\text { Oil-polluted soil } \\
\text { collected from an oil } \\
\text { refinery was mixed } \\
\text { with a farm soil at } \\
\text { the ratio of } 1: 1 \text { to } \\
\text { prepare soil sample } \\
\text { with PAH } \\
\text { concentration of } \\
37.8 \mathrm{mg} \mathrm{kg}^{-1} \text { dry } \\
\text { soil. }\end{array}$ & $\begin{array}{l}\text { Maximum shoot and } \\
\text { root dry weight were } \\
\text { observed in the } \\
\text { addition of } \mathrm{P} 12 \text { to } \\
\text { contaminated soil } \\
\text { ( } 6.62 \text { and } 2.23 \mathrm{~g} \\
\text { pot }^{-1} \text {, respectively). } \\
\mathrm{P} 12 \text { was also the } \\
\text { most ACC } \\
\text { deaminase producer } \\
\text { strain among the } \\
\text { five. } \\
\text { Additionally, the } \\
\text { most effective } \mathrm{PAH} \\
\text { removal was } \\
\text { reported in the pots } \\
\text { inoculated with } \mathrm{P} 12 \\
\text { ( } 74.9 \%) \text {. }\end{array}$ & $\begin{array}{l}\text { Rezvani } \\
\text { Borujeni et } \\
\text { al. (2018) }\end{array}$ \\
\hline
\end{tabular}

